\title{
Global Economic Growth and Expected Returns around the World \\ The End-of-the-year Effect
}

Møller, Stig Vinther; Rangvid, Jesper

\author{
Document Version \\ Accepted author manuscript \\ Published in: \\ Management Science \\ DOI: \\ 10.1287/mnsc.2016.2589 \\ Publication date: \\ 2018 \\ License \\ Unspecified
}

Citation for published version (APA):

Møller, S. V., \& Rangvid, J. (2018). Global Economic Growth and Expected Returns around the World: The Endof-the-year Effect. Management Science, 64(2), 573-591. https://doi.org/10.1287/mnsc.2016.2589

Link to publication in CBS Research Portal

\section{General rights}

Copyright and moral rights for the publications made accessible in the public portal are retained by the authors and/or other copyright owners and it is a condition of accessing publications that users recognise and abide by the legal requirements associated with these rights.

\section{Take down policy}

If you believe that this document breaches copyright please contact us (research.lib@cbs.dk) providing details, and we will remove access to the work immediately and investigate your claim.

Download date: 26. Apr. 2023

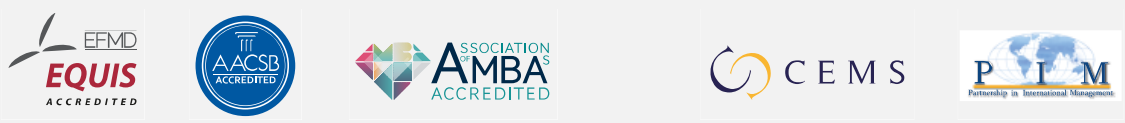




\section{Global Economic Growth and Expected Returns around the World: The End-of-the-year Effect}

\section{Stig Vinther Meller and Jesper Rangvid}

Journal article (Post print version)

CITE: Global Economic Growth and Expected Returns around the World : The End-of-the-year Effect. / Møller, Stig Vinther; Rangvid, Jesper. In: Management Science, 21.11.2016.

DOl: 10.1287/mnsc.2016.2589

Uploaded to Research@CBS: January २०17 


\title{
Global economic growth and expected returns around the world:
}

\author{
The end-of-the-year effect*
}

\author{
Stig V. Møller ${ }^{\dagger} \quad$ Jesper Rangvid
}

July 2016

\footnotetext{
${ }^{*}$ We thank John Campbell, Peter Christoffersen, Lubos Pastor, Maik Schmeling, two anonymous referees and the Associate Editor, as well as seminar participants at Glasgow University, HEC Paris, SDU, St. Gallen University, the AP2-CFF conference on return predictability, and the Arne Ryde Workshop in Financial Economics for useful comments. Møller acknowledges support from CREATES - Center for Research in Econometric Analysis of Time Series (DNRF78), funded by the Danish National Research Foundation.

${ }^{\dagger}$ CREATES, Aarhus University, Fuglesangs Allé 4, 8210 Aarhus, Denmark. Phone: (45) 87164825 and e-mail: svm@econ.au.dk.

${ }^{\ddagger}$ Department of Finance, Copenhagen Business School, Solbjerg Plads 3, 2000 Frederiksberg, Denmark. Phone: (45) 38153615 and e-mail: jr.fi@cbs.dk.
} 


\title{
Global economic growth and expected returns around the world: The end-of-the-year effect
}

\begin{abstract}
Global economic growth at the end of the year strongly predicts returns from a wide spectrum of international assets, such as global, regional, and individual-country stocks, FX, and commodities. Global economic growth at other times of the year does not predict international returns. Low growth in the global economy at the end of the year predicts higher returns over the following year. It also predicts the global business cycle. When global economic growth at the end of the year is low, investors expect a worsening of the global business cycle and increase their required returns.
\end{abstract}

Keywords: $\quad$ End-of-the-year global economic growth, expected returns, international business cycle, in-sample and out-of-sample international return forecasts. JEL-classification: E44; G12; G14 


\section{Introduction}

Growth in the global economy at the end of the year strongly predicts returns around the world, whereas global economic growth at other times of the year does not predict international returns. To provide a brief glimpse of this overall message of our paper, consider Fig. 1 below. It shows in the left-hand graph average annual real stock returns from twelve developed countries conditioned on global economic growth during the last quarter of the previous year for the 1970-2013 period. The average (across countries and time) annual real stock return is 8.6\% (the column labelled "All" in the left-hand graph of Fig. 1), but the return realized in a given year depends on global economic growth at the end of the previous year. When global economic growth during the last quarter (Q4) of the previous year has been low (below the median growth rate; the column labelled "Low"), average real returns over the following year have been high at $12.3 \%$. When growth has been high (above the median growth rate; labelled "High"), average returns have been low at 4.8\%. There is a clear pattern: Stock returns around the world are higher during years where global economic activity at the end of the previous year was low. We show that this relationship is statistically strong and robust and holds across asset classes and countries. We also show that global economic growth at other times of the year, e.g., the middle or the beginning of the year, does not predict returns. This is illustrated in the right-hand graph of Fig. 1 where we show average returns realized one year ahead conditioned on global economic growth during the first (Q1), second (Q2), and third (Q3) quarter of the year. We find that regardless of whether global economic growth is high or low in the beginning or the middle of the year, subsequent returns are more or less the same.

We analyze returns from a wide range of stock markets, such as individual-country stock markets (developed and emerging), the world stock market portfolio, regional stock market portfolios, and other kinds of stock market portfolios. We analyze both in-sample and out-of-sample forecasts. We also study different asset classes such as foreign exchange and commodities. For 28 out of the 30 stock markets we analyze, we find a strong negative relation between end-ofthe-year global economic growth and expected returns. The same holds true for returns on the world market portfolio, regional portfolios (e.g., the European or Pacific portfolios), as well as 

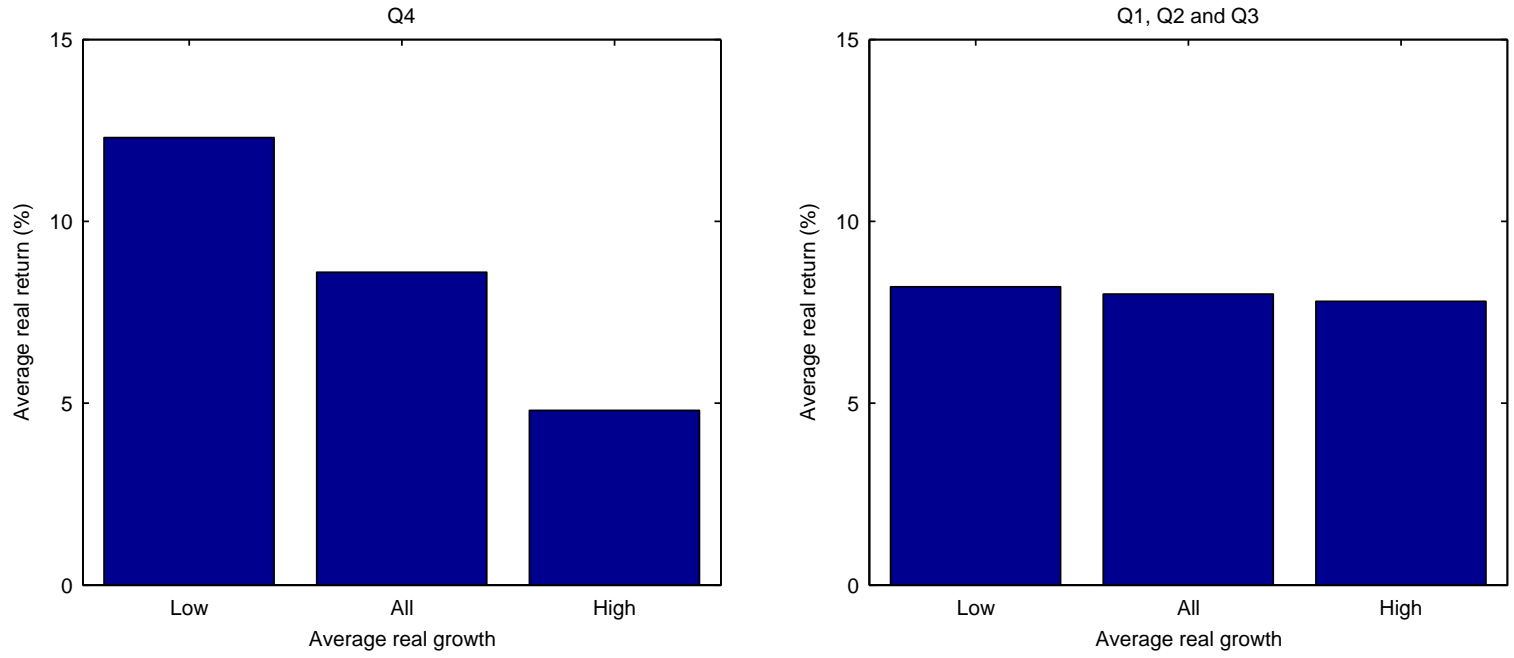

Figure 1: End-of-the-year (Q4) real global economic growth and next year's real global stock return (lefthand graph). Real global economic growth during the first, second, and third quarter and subsequent one-year real stock returns (right-hand graph).

foreign exchange and commodity return portfolios.

The statistical significance of our findings is remarkable. When predicting returns with global economic growth during the first parts of the year, the $t$-statistics to the in-sample predictive regression coefficients are generally below 2 in numerical terms, i.e. seldom statistically significant. When predicting with end-of-the-year (EOY) global economic growth, we often find $t$-statistics around 5 in numerical terms, i.e. significant at a $0.001 \%$ significance level.

Goyal and Welch (2008) show that it is difficult to predict US stock market returns out-ofsample. When we use benchmark predictive variables that have been shown to forecast, e.g., US returns, such as the global dividend-price ratio, a short interest rate, or $\widehat{c a y}$ (Lettau and Ludvigson, 2001), as well as global economic growth during the first parts of the year, we find that the Goyal-Welch result extends to international data, i.e. these variables do not forecast international returns out-of-sample better than the historical mean of returns. On the other hand, EOY global economic growth predicts stock market returns around the world better out-of-sample than the prevailing-mean model. 


\subsection{Reasons behind results}

We show that EOY global economic growth is a strong business cycle indicator, as it predicts the future global output gap. The output gap measures the cyclical component of economic activity, i.e. the business cycle. We find that EOY global economic growth predicts the global output gap with a positive sign, i.e. an improvement in EOY global economic activity predicts an improvement in the global business cycle over the following year. Global economic growth at other times of the year does not predict global output gaps well. ${ }^{1}$

When EOY global economic growth predicts the global business cycle, investors adjust their return expectations. But do expected returns change because cash-flows or discount rates change, i.e. what is the economic mechanism? To answer this question, we show that global EOY growth predicts the dividend-price ratio with a positive sign, whereas it does not predict dividend growth. When future dividend growth rates, and thus cash-flows, do not move when EOY growth moves, the fall in expected stock prices that makes the expected dividend-price ratio increase results from a change in discount rates (Cochrane, 2011). The fall in expected stock prices is consistent with the reduction in expected returns that an increase in global EOY growth predicts.

We check whether local EOY economic growth is a stronger predictor of local returns than global EOY growth, i.e. whether, e.g., German EOY economic growth matters more for German returns than global EOY growth. This hypothesis is not supported by the data. We find that local EOY economic growth contains less explanatory power for international returns compared to global EOY economic growth. This implies that a contributing reason why we find strong return-predictability results is that we use global, and not local, EOY economic growth to predict international returns. Further exploring this finding, we show that returns in countries that trade more with other countries, i.e. more open countries, are more affected by global EOY economic growth. Finally, we show that stock returns of firms in cyclical sectors react

\footnotetext{
${ }^{1}$ The result that economic growth at the end of the year is a strong business cycle indicator relates to results in Barsky and Miron (1989), Beaulieu et al. (1992), Beaulieu and Miron (1992), and Wen (2002) that economic activity at the end of the year contains special information about the business cycle. These papers do not investigate the implications of EOY economic growth movements for expected returns.
} 
stronger to EOY economic growth than returns of firms in defensive sectors.

Overall, our finding of a negative relation between a strong business cycle indicator (EOY global economic growth) and subsequent returns provide evidence in support of countercyclical variation in risk premia. Such variation is a key feature of many prominent consumption- and production-based asset pricing models (see Mehra, 2008). The international evidence in our paper is similarly consistent with the international production-based modelling framework of Zhou and Zhu (2015), who derive a model in which local-country expected returns depend upon expected global business cycle conditions.

\subsection{Related literature}

In addition to already mentioned literature, our paper adds to an emerging literature that investigates the role of end-of-the-year business cycle activity for asset prices. Møller and Rangvid (2015) show that US EOY economic growth predicts US returns, whereas US economic activity during the rest of the year does not. Jagannathan and Wang (2007) and Jagannathan, Marakani, Takehara, and Wang (2012) use EOY growth in consumption to improve the performance of the static consumption-CAPM using data for the US, the UK, and Japan. Da, Yang, and Yun (2014) use US EOY growth in electricity consumption to capture the cross-sectional distribution of returns in the US and Da, Huang, and Yun (2015) use EOY growth in electricity consumption to predict time-series movements in returns, examining data from the US, Japan, and the UK.

Jagannathan and Wang (2007) and Møller and Rangvid (2015) suggest that the concentration of cultural (Christmas and New Year) and institutional (year-end bonuses and the end of the tax year) events at the end of the year implies that some investors are more likely to make savings and portfolio choice decisions at the end of the year. We document in this paper that EOY global economic growth contains information about the future business cycle. This suggests that it is not the mere concentration of institutional and cultural events at the end of the year that makes investors pay particular attention to global EOY economic growth; there 
might also be good economic reasons for doing so. ${ }^{2}$

Our paper also contributes to the literature that examines the relation between international macro variables and expected global returns. Bakshi, Panayotov, and Skoulakis (2014) show that the growth rate of the Baltic Dry Index predicts international returns. They also show that the reason is that it also predicts global economic activity, similar in spirit to our finding that EOY global economic growth predicts global returns because it predicts the global business cycle. Zhou and Zhu (2015) show that global leading economic indicators predict global bond returns. In accordance with our finding that global, and less so local, EOY economic activity matters for global returns, Zhou and Zhu (2015) also provide a rational asset pricing model explaining why global economic conditions should matter for returns in individual countries. Cooper and Priestley (2009) find that output gaps in individual G-7 countries predict returns in individual G-7 countries and Cooper and Priestley (2014) show that the global capital stockoutput ratio predicts international returns. Rodriguez, Restoy, and Pena (2002) and Rapach, Rangvid, and Wohar (2005) find low predictive power of economic growth in individual countries for returns in individual countries.

We take the literature that investigates the special asset implications of EOY economic activity and the literature that examines the relation between international macro variables and global returns further by examining return and business cycle predictability by EOY global economic growth in a large international dataset. This allows us to document that the relation between global economic growth and expected returns around the world is strong at the end of the year and non-existing at other times of the year, exists in many countries, and extends across different asset classes. ${ }^{3}$

The paper is organized as follows. In the next section, we describe the data we use. In

\footnotetext{
${ }^{2}$ There are countries where the tax year ends, e.g., in April, such as the UK, and countries where New Year is celebrated in January/February, such as Asian countries that celebrate the Chinese New Year. In accordance with our result that global EOY economic growth predicts the global business cycle, we find a strong relation between end-of-the-year economic growth and expected returns both in countries where the end of the tax year, New Year, etc. are concentrated at the end of the calendar year, as well as in countries where some of these events are distributed across the year.

${ }^{3}$ In relation to Møller and Rangvid (2015), which is the paper closest to ours, we provide in this paper new evidence that global rather than local EOY economic growth predicts returns, EOY economic growth also predicts the business cycle, and the end-of-the-year effect prevails around the world and across international asset markets.
} 
Section 3, we thoroughly show that global EOY economic growth predicts returns around the world. In Section 4, we show that it is global EOY economic growth that predicts returns and to a lesser extent local and US EOY growth. Section 5 examines possible explanations for our results. In Section 6, we discuss results for countries where institutional and cultural activities are distributed across the year. We present results from a host of robustness tests in Section 7. A final section concludes.

\section{Data}

In our main tests, we predict returns using economic growth and benchmark predictive variables.

Returns. Stock returns are calculated from MSCI total return indexes, available since 1970. Our data sample ends in 2013. We analyze returns on the world market portfolio, regional portfolios, and individual-country portfolios. The regional portfolios are the European portfolio, the Pacific portfolio, and the EAFA (Europe, Australia, Far East) portfolio. Full-sample, i.e. 1970-2013, data on returns and economic growth exist for twelve individual developed countries: Australia, Belgium, Canada, France, Germany, Italy, Japan, Netherlands, Sweden, Switzerland, the UK, and the US. These are the twelve countries we use in Fig. 1 in the Introduction. In addition, we analyze return data from 18 markets for which we can get at least 20 years of return data: Argentina, Brazil, Chile, Czech Republic, Hong Kong, Hungary, India, Indonesia, Korea, Malaysia, Mexico, Peru, Philippines, Poland, Russia, Singapore, Taiwan, and Thailand.

When examining global and regional stock market portfolios, we analyze both nominal returns, real returns, and excess returns in USD. We use the US 3-month T-bill rate as a proxy for the risk-free rate when calculating excess returns in USD. We deflate nominal returns with the US inflation rate when calculating real returns.

When analyzing individual-country stock market returns, we focus on real returns, as appropriate proxies for risk-free rates are not sufficiently available at a quarterly frequency for all individual countries. We deflate nominal returns in local currencies with local-country inflation, 
so that we analyze real returns in local currencies.

We also investigate foreign exchange and commodity returns. We construct currency portfolio returns following the procedure outlined in Lustig, Roussanov, and Verdelhan (2011). We let $s_{t}^{i}$ denote the $\log$ of the spot price of currency $i$ at time $t$ in units of foreign currency per US dollar, and we let $f_{t \rightarrow t+1 y}^{i}$ denote the log of the corresponding 1-year ahead forward exchange rate at time $t$. We compute the log currency excess return for a US investor at the annual horizon for currency $i$ as: $r_{t+1 y}^{i}=f_{t \rightarrow t+1 y}^{i}-s_{t+1 y}^{i}$. For a basket of $N$ currencies the $\log$ excess currency portfolio return is given by $\bar{r}_{t+1 y}=\frac{1}{N} \sum_{i=1}^{N} r_{t+1 y}^{i}$. We form three portfolios: currency returns from developed markets, emerging markets, and all countries. Determined by data availability, the developed markets are Australia, Canada, Germany (after 1999, we use the euro), Japan, New Zealand, Norway, Sweden, Switzerland, and the UK. The emerging markets are the Czech Republic, Hong Kong, Hungary, India, Mexico, Philippines, Singapore, South Africa, Taiwan, and Thailand. Our FX data are from Datastream and start around 1985.

To compile our index of commodity returns, we use spot prices on 19 different commodities: coffee, corn, cotton, hogs, sugar, wheat, wool, aluminium, copper, gold, lead, nickel, platinum, silver, zinc, crude oil, natural gas, lumber, and fish (all denoted in US dollars). Returns to commodities are the growth rates in spot prices. Our commodity return series is an equal-weighted portfolio of the 19 individual return series. We also investigate excess returns to commodities by subtracting the short US rate from the commodity return series. Our commodity data are from Datastream and start around 1980.

Economic growth. We predict returns with global growth in industrial production. Our data for seasonally adjusted industrial production are from the OECD. We have full-sample (i.e., 1970-2013) information on industrial production for the twelve developed countries mentioned above. Our main measure of global economic growth is the equal-weighted average of industrial production growth in these twelve countries. We calculate quarterly growth rates using endof-quarter values of industrial production. We focus on quarterly growth rates of industrial production because we get a more precise estimate of expected returns using economic growth 
during the last quarter of the year compared to using, e.g., only December economic growth. We return to these points in Section 7 where we discuss results from using monthly growth rates of global industrial production to predict international returns, as well as other robustness checks on our calculation of global economic growth. In Section 7, we also mention results from tests where we use GDP, which only is available at a quarterly frequency, though, to predict returns.

Trade openness. In Section 4, we sort countries according to trade openness. We consider three measures of trade openness: exports over GDP, imports over GDP, and the sum of exports and imports over GDP. We obtain these data from the OECD database.

Benchmark predictive variables. We compare the return-predictive ability of economic growth with a set of standard predictive variables often used in the literature. We use the dividend-price ratio on the MSCI world portfolio (see, e.g., Campbell and Shiller, 1988), the $\widehat{c a y}$-ratio of Lettau and Ludvigson (2001), the short term interest rate (see, e.g., Campbell, 1991), and the inflation rate (see, e.g., Fama and Schwert, 1977). As short-term interest rate, we use a short US T-bill rate. Inflation is the equal-weighted rate of annual inflation in the twelve developed countries, calculated from the consumer price index (all items) available from the OECD database.

\subsection{Summary statistics}

Table 1 shows summary statistics. We show the time-series averages, standard deviations, and first-order autocorrelation coefficients. In Panel A, we show statistics for the predictive variables. Global industrial production has generally been growing with around $0.3 \%$ to $0.5 \%$ on average per quarter, with standard deviations of around $1 \%$ to $2 \%$. There are no particularly noteworthy differences between the average growth rates in the different quarters. End-of-the-

year economic growth $\left(I P^{4}\right)$ is slightly more volatile than growth during the other quarters, though.

Regarding the benchmark variables, average annual inflation has been around $4 \%$, the av- 
erage annualized US T-bill rate has been around $5 \%$ over the total sample period, and the DP ratio of the world market portfolio has been around $3 \%$ on average.

The AR1 coefficients of the growth rates of global industrial production are low compared to the AR1 coefficients of the benchmark variables. In numerical terms, the AR1 coefficients of global industrial production growth are in the range from 0.13 to 0.23 , whereas the benchmark predictive variables are much more persistent with AR1 coefficients between 0.87 and 0.92 . Given the general concern in the return-predictability literature that persistent predictive variables can give rise to biased estimates and $t$-statistics (e.g., Stambaugh, 1999), it is reassuring that this is not a concern for the global industrial production growth rates that we focus on in this study.

Panel B shows summary statistics for stock returns from the twelve developed countries for which we have full sample data, together with summary statistics for FX and commodity returns. All stock returns (world, regional, and individual country) in Table 1 are real returns, whereas FX and commodity returns are excess returns. Average regional real stock returns vary between $7 \%$ and $9 \%$ with standard deviations of $18 \%$ to $29 \%$. Average real individual-country returns show a wider spread from $5 \%$ in Italy to $13 \%$ in Sweden. FX returns have on average been around $2 \%$ and commodity returns around $0.5 \%$. All returns show low persistence.

\section{Global end-of-the year economic growth predicts returns around the world}

We start by estimating the in-sample regression:

$$
R_{t+1}=\alpha+\beta I P_{t}^{i}+\varepsilon_{t+1}
$$

where $R_{t+1}$ is the one-year-ahead return and $I P_{t}^{i}$ is the quarter $i$ growth rate of global industrial production. In Table 2, Panel A, we predict nominal returns, excess returns, and real returns on the world and regional portfolios. When $i=4$, i.e. when we use the growth rate in global 
industrial production at the end of the year (from the third to the fourth quarter), the oneyear-ahead return is measured over the calendar year. When $i=3$, i.e. when we use the growth rate in global industrial production from the second to the third quarter, the one-year-ahead return is measured from the beginning of the fourth quarter to the end of the third quarter next year, and so on for $i=2$ and $i=1$. For each regression, we report the slope estimate, the Newey-West (1987) corrected $t$-value (truncated at lag 1; our results are very robust toward other choices of truncation lags), and the $R^{2}$ statistic.

To explain the results in Table 2, consider, e.g., the results for nominal returns on the world market portfolio during the calendar year predicted by EOY (Q4) economic growth, repeated here for convenience:

$$
R_{t+1}=\hat{\alpha}-3.1 I P_{t}^{4}+\hat{\varepsilon}_{t+1}, \quad t\left(I P_{t}^{4}\right)=-4.3, \quad R^{2}=11.3 \% .
$$

A one percentage point increase in global economic activity at the end of the year has on average been associated with a 3.1 percentage point reduction in the return on the world market portfolio over the following year. This effect is strongly statistically significant with a $t$-statistic of -4.3 . Variation in global EOY economic growth accounts for $11.0 \%$ of the variation in one-year ahead calendar-year returns of the world market portfolio. Consider next the relation between global economic growth during, respectively, the first, the second, and the third quarter of the year and subsequent one-year ahead returns. Table 2 shows that one-year ahead returns realized after the first, the second, and the third quarter have had no systematical relation to global economic growth during these quarters, as the predictive coefficients are insignificant ( $t$-statistics are below one in numerical terms). Together, these two findings imply that EOY global economic growth strongly and significantly influences next year's returns on the world market portfolio negatively, whereas economic growth at other times of the year does not affect expected returns.

The negative influence from EOY economic growth on the return on the world market portfolio also appears if we consider excess returns and real returns; the $t$-statistic is -5.3 for excess returns and -4.4 for real returns. And, similarly, regardless of whether we examine nominal, real, or excess returns, global economic growth during the first, second, or third 
quarter does not predict returns on the world market portfolio.

There are no overlapping observations in our regressions (we have one observation per year) and our regressor is not persistent, as mentioned in Section 2. This means that the usual concerns regarding inference in return-predicting regressions (see Rapach and Zhou, 2013, for an overview) should be less of an issue in our setting. To be on the safe side, we nevertheless investigated alternatives to the Newey-West adjustment with one lag that we rely on in our base regressions, such as automatic lag selection in the Newey-West procedure (Newey and West, 1994), as well as Hansen-Hodrick (1980) and Hodrick (1992) standard errors. In all cases, EOY global economic growth is significant and economic growth during other quarters is not. The results are available upon request. In addition, we conduct a comprehensive bootstrap analysis to investigate the small-sample properties of the estimated regression coefficients. We mention these results in Section 7.

Møller and Rangvid (2015) find similar results for the relation between US returns and US economic growth. The US stock market has a high weight in the world market portfolio (55\% in July 2014). Hence, one might wonder whether the results for the world market portfolio are driven by the US. This is not the case. If we concentrate on the European portfolio, the EAFA, or the Pacific portfolio, i.e. regional portfolios that do not include the US stock market, we find the same pattern. We also include all the portfolio returns in a panel and show the results under the heading "All returns. Panel regressions". Standard errors used to calculate $t$-statistics are two-way cluster-robust (cluster by year and by country) in order to account for both time series and cross-sectional dependence, see Thompson (2011). We find a strong end-of-the-year effect also in the panel regressions. We conclude that regardless of whether we look at nominal, real, or excess returns, and regardless of whether we concentrate on the European, the Pacific, the EAFA, or the world market portfolio, EOY global economic growth strongly affects one-year ahead returns, whereas there are no such effects at other times of the year.

We conduct a host of robustness tests with respect to the basic design of the regressions. For instance, we find that the results are robust to taking into account publication lags of data on economic growth, robust towards using monthly instead of quarterly economic growth rates, 
hold when accounting for potential small-sample biases in the estimations, robust towards calculating global economic growth in different ways (e.g., GDP-weighted instead of equalweighted), hold in both expansions and recessions, robust towards using innovations to (news about) the EOY global economic growth rate instead of the growth rate itself, etc. We delegate the more detailed description of the results from these robustness tests to Section 7 .

We check the extent to which international stock market returns are generally predictable using variables that in the literature have been shown to predict returns, such as the DPratio, $\widehat{\text { cay }}$, etc. The results are in Panel B for returns on the world market portfolio. Results for regional returns are similar. Few of the variables are significant and the overall evidence on return predictability from benchmark predictive variables is weak. In light of this, it is remarkable that $t$-statistics associated with EOY global economic growth generally exceed four and often approach five (in numerical terms), i.e. indicate strong statistical significance.

\subsection{Results for individual-country returns}

Global EOY economic growth also predicts returns from stock markets of individual countries. Panel A of Table 3 shows results for the twelve developed countries for which return and economic growth data are available for the full sample. We find that EOY global growth is a significant predictor of real returns in ten out of the twelve countries. The $t$-statistics range from a low of -1.5 in Italy to a high (in absolute terms) of -4.1 in the Netherlands, and the $R^{2}$ s range from $1.3 \%$ in Italy to impressing $23.5 \%$ in the UK. Equally important, we find that global economic growth at other times of the year predicts returns significantly in only a few instances: There are a few significant non-EOY coefficients here and there (Q1 in Australia, Q2 in Japan, Q1 in the Netherlands, Q2 in Sweden, and Q1 in the UK), but the general impression is that there is no systematic pattern. We return to this in Sections 5 and $7 .^{4}$ When including all developed countries, i.e. the countries for which we have full sample information, in a panel regression, we find that EOY global economic growth predicts returns, whereas economic growth

\footnotetext{
${ }^{4}$ The reason why $I P^{1}$ sometimes predicts returns is because $I P^{1}$ is correlated with $I P^{4}$. In Section 7 , we explain that when conditioning on $I P^{4}, I P^{1}$ loses its predictive power in those cases where it is otherwise significant.
} 
during the rest of the year does not (panel regression results are in the row "All").

For emerging markets, we have data for shorter samples. Panel B of Table 3 shows the results. We find that EOY global economic growth is a strong predictor of returns in all 18 countries. EOY global economic growth predicts returns significantly with $t$-statistics ranging from -2.0 in the Czech Republic to -5.0 in Hungary and $R^{2}$ s range from $4.1 \%$ in the Czech Republic to $25.7 \%$ in Taiwan. We also notice, like for developed countries and regional and global portfolios, that the predictive coefficient is estimated to be negative, i.e. high EOY global economic growth is followed by lower returns on stock markets around the world. There are no systematic relations between economic growth and expected returns during the rest of the year. There are a couple of significant coefficients to $I P^{1}$, but no clear systematic pattern, and $I P^{1}$ loses its predictive power when conditioned on $I P^{4}$, as we mention in robustness tests in Section 7 .

As mentioned, the country returns we use to generate Table 3 are in local currencies. The returns we otherwise consider in the paper - returns from international portfolios (world portfolio, European portfolio, etc.), commodity returns, FX returns, and so on - are all seen from the point of view of a US investor, i.e. in USD. We did a robustness test where we use country excess returns in USD for the twelve countries for which we have data over the full sample. We find results similar to those in Table 3, i.e. EOY global economic growth predicts country returns in USD with a negative sign whereas economic growth at other times of the year is insignificant. There are two important implications of these results: first, when EOY economic growth predicts returns both in USD and local currencies, the EOY effect is not merely reflecting a USD effect, but rather a movement in underlying returns. ${ }^{5}$ Second, the sign to the predictive coefficient is consistently estimated to be negative across assets and currencies. This supports our interpretation, that we further develop in Section 5, of a time-varying risk premium.

In total, Table 3 shows results for 30 individual countries; 12 developed countries for which we have return and economic growth data for the full 1970-2013 period and 18 emerging coun-

\footnotetext{
${ }^{5}$ This is verified by similar results available upon request where we forecast the world-market portfolio in other currencies than the USD, i.e. the world-market portfolio in Euros, in Canadian dollar etc.
} 
tries for which we have at least 20 years of return data. We find a significant EOY effect in 28 of these 30 countries. For regional and world portfolios (Table 2), we find a significant EOY effect in all cases. Hence, the EOY effect is persuasive, statistically strong, and robust across most stock markets around the world.

\subsection{Foreign exchange and commodities}

Foreign exchange (FX) and commodities differ from stocks in several important dimensions. For instance, listed firms publish annual reports and the fiscal year ends in December for most firms. Listed firms are also subject to requirements by stock exchanges. Moreover, stocks are traded by both retail and institutional investors, whereas FX and commodities are more difficult to trade for retail investors. In spite of such differences, we also find an end-of-the-year effect for FX and commodities.

\subsubsection{FX returns}

The FX returns are calculated following the procedure outlined in Section 2. We use global economic growth to predict currency returns from developed, emerging, and all countries. The results from the predictive regressions are shown in Panel A of Table 4. We find that returns on the three currency portfolios are predictable by EOY global economic growth with $t$-statistics ranging from -2.4 to -2.8 . The estimated coefficients are negative, as in Tables 2 and 3 (for stock markets), i.e. expected returns on FX are low when EOY global economic activity is high. For EOY global economic growth during the first, second, and third quarter, we find no systematic relation between economic growth and currency returns.

\subsubsection{Commodities}

In Panel B of Table 4, we show results from regressions of commodity returns on lagged global economic growth. EOY global economic growth is a strong predictor of returns on commodities with $t$-statistics around -5 , while there is no significant predictability of commodity returns 
throughout the rest of the year.

\subsection{Global end-of-the year growth also predicts international stock portfolios out-of-sample}

Goyal and Welch (2008) argue that strong in-sample predictability results do not necessarily indicate that investors can expect to benefit from trading on the signals generated by in-sample regressions. Goyal and Welch find that typical variables used to predict returns on the US stock market in-sample (such as the short interest rate, dividend yield, etc.) turn out to be insignificant in out-of-sample evaluations. In this section, we show that EOY global economic growth predicts international stock market returns out-of-sample, whereas global economic growth at other times of the year does not.

We reserve the period 1970-1989 to initial estimation such that the out-of-sample forecasts are made over the 1990-2013 period. Given that we need a sufficiently long sample for these out-of-sample evaluations, we study in this section those twelve countries for which we have full-sample information, as well as regional and world market portfolios for which we also have 1970-2013 return data. We evaluate whether our return-predictions are more precise than predictions from the prevailing-mean model, i.e. a benchmark model where the historical mean of returns at each point in time is used as predictor of next period's return. To measure the precision of the predictions, we consider each model's absolute and squared prediction errors. More specifically, we evaluate whether the ratio $L_{U} / L_{R}$ is statistically smaller than one, where the loss $L$ of making a wrong forecast refers to either the mean absolute forecast error (MAE) or the mean squared forecast error (MSE), subscript $U$ refers to the unrestricted model, and subscript $R$ refers to the restricted model where we use the prevailing mean to predict. If $L_{U} / L_{R}$ is statistically smaller than one, the forecast accuracy of the variable we consider is superior to that of the prevailing mean.

We test the null hypothesis of equal predictive accuracy using the Diebold and Mariano (1995) t-statistic (using Newey-West standard errors with one lag). We compare nested models; basically, we are comparing forecasts from recursively estimated unrestricted models like $\hat{R}_{t+1}=$ 
$\widehat{\alpha_{t}}+\widehat{\beta}_{t} x_{t}$ with those from restricted models like $\hat{R}_{t+1}=\widehat{\alpha_{t}}$, with $\widehat{\alpha_{t}}$ and $\widehat{\beta}_{t}$ estimated using data up to time $t$. Clark and McCraken (2011) use Monte Carlo simulations to show that the Diebold-Mariano test is actually a conservative test in settings where nested models are compared. ${ }^{6}$ Finally, in order to gauge the economic importance of our predictability results, we show Campbell and Thompson (2008) out-of-sample $R^{2}$ s when predicting with EOY global economic growth.

When testing the out-of-sample predictions, we move the returns we predict one quarter ahead to take publication lags of data for industrial production into account and thereby closer resemble the situation of a real-time investor. In Section 7, we discuss in-sample results where we similarly move returns forward by one quarter to account for publication lags.

Table 5 shows the out-of-sample results. To explain, consider the mean absolute errors from predictions of real returns on, e.g., the world portfolio in Panel A. The MAE ratio equals 0.89 when using global EOY economic growth to predict. This implies that the out-of-sample absolute forecast errors generated by EOY global economic growth are on average around $11 \%$ smaller than those generated by the prevailing mean model. Table 5 also shows that this difference is statistically significant at the $10 \%$ level. The same results are found for the regional portfolios. EOY global economic growth also predicts returns from the majority of the individual-country portfolios significantly better than the prevailing mean model out-of-sample. We find that the MAE ratios are always lower than one when using global EOY growth to predict real returns on individual-country portfolios and in most cases significantly so. We also find that $I P^{1}, I P^{2}$, and $I P^{3}$ do not predict returns better than the prevailing mean model (there is only one case where the prevailing mean model significantly underperforms the unrestricted model). Panel B shows result using mean squared prediction errors. The statistical evidence is marginally weaker than for MAE, but the overall conclusions remain the same: $I P^{4}$ often produces significantly better forecasts than the benchmark model, whereas $I P^{1}, I P^{2}$, and $I P^{3}$ produce predictions that are far from being significant. ${ }^{7}$

\footnotetext{
${ }^{6}$ We have checked the results using the Clark-West (2007) test that is sometimes used for nested models. We get slightly weaker statistical evidence using this procedure. Typically, we get $p$-values around $10 \%$ when using EOY variables to predict. The other variables remain clearly insignificant.

${ }^{7}$ These results are consistent with the findings for the US in Møller and Rangvid (2015) that US Q4 economic growth is a significant predictor of US returns out-of-sample, whereas US economic growth at other times of the
} 
The out-of-sample $R^{2}$ is $18.2 \%$ when predicting real returns on the world-market portfolio with EOY global economic growth. ${ }^{8}$ Campbell and Thompson (2008) show that the ratio of the OOS $R^{2}$ and the squared Sharpe ratio for the portfolio that is predicted provides an estimate of the increase in return that can be obtained for a mean-variance investor if this investor relies on information by the predictive variable when making portfolio decisions. The squared Sharpe ratio on the world-market portfolio is $9.3 \%$. This implies that a mean-variance investor would increase the annual return by a proportional factor of about 2 if relying on EOY global economic growth. The out-of-sample predictability captured by EOY global economic growth is economically important, too. ${ }^{9}$

In Panel C, we show results where we use the benchmark predictive variables to predict returns on the world market and regional portfolios out-of-sample. We find that there is no case in which the benchmark variables predict significantly better than the prevailing-mean model. This finding for the benchmark predictive variables is reminiscent of the Goyal and Welch (2008) finding that it is difficult for standard variables to predict returns out-of-sample significantly better than the prevailing-mean model. Goyal and Welch (2008) use US variables to predict US returns. We show that their finding extends to a global setting when using global economic growth during other quarters than the fourth quarter and standard benchmark variables to predict returns. EOY global economic growth, on the other hand, predicts international returns out-of-sample with statistically superior accuracy compared to the prevailing-mean model.

\section{Global growth}

We find strong predictability results because we use a global measure of economic growth. Had we used local-country economic growth, or for that matter US economic growth, to predict

year is not. For the US, one can download long samples of vintage data, i.e. data available to the investor in real time. Using vintage US data, Møller and Rangvid (2015) show that US EOY economic growth is a significant predictor, i.e. an investor could have benefitted from exploiting the information in EOY economic growth in real time. Vintage data are unfortunately not available for most of the 12 countries we study here.

${ }^{8}$ When predicting with $I P^{1}, I P^{2}$, and $I P^{3}$, OOS $R^{2}$ s are close to zero. To save space we do not show these OOS $R^{2}$ s.

${ }^{9}$ Campbell and Thompson (2008) do their calculations for forecasts of excess returns. If we predict excess returns on, e.g., the world market portfolio, we find an OOS $R^{2}$ of $20.5 \%$, i.e. even higher than if we forecast real returns. 
returns in local stock markets, our predictability results would not have been as strong.

To show this, we compare the extent to which individual-country returns are predictable by own-country economic growth, US economic growth, global economic growth, and own-country economic growth adjusted for global economic growth. The results are in Table 6 . We only present results from regressions that use EOY economic growth; global economic growth rates at other times of the year are not significant predictors of returns, as demonstrated in the previous parts of the paper. For convenience, and ease of comparison with new results, we repeat the results from Table 3 where we use EOY global economic growth to predict returns in the $I P_{W}^{4}$ columns of Table 6 . Compare these results with those in the $I P_{U S}^{4}$ columns where we predict individual-country returns with US EOY economic growth. We find that US growth is significant in Australia, Netherlands, Switzerland, the UK, and the US. This implies that return predictability captured by global EOY growth in Belgium, Canada, France, Germany, and Sweden disappears when replacing global EOY growth with US EOY growth. We also find that for those countries where US growth is a significant predictor (Australia, Netherlands, Switzerland, UK, and US), the statistical support of predictability is generally weaker (lower $t$-statistic and $R^{2}$ ) compared to using global economic growth. Hence, US economic growth at the end of the year is generally not as strong a predictor of individual-country returns as global EOY economic growth.

The $I P_{L}^{4}$ columns of Table 6 show that local EOY economic growth $\left(I P_{L}^{4}\right)$ forecasts returns in several countries. Here we use Australian EOY economic growth to predict Australian returns, and so on. Local economic growth is influenced by growth in the global economy, however. The average correlation coefficient between local EOY economic growth and global EOY economic growth is 0.73 , ranging from a low correlation of 0.52 between Australian and global EOY growth to a high correlation of 0.88 between German and global EOY growth. To evaluate how much independent explanatory power is left by local EOY growth rates after controlling for the information in global growth, we orthogonalize local EOY growth with respect to global EOY 
growth by running the regression:

$$
I P_{L_{i}, t}^{4}=\alpha+\beta I P_{W, t}^{4}+I P_{L_{i}^{\perp}, t}^{4}
$$

where $I P_{L_{i}, t}^{4}$ is EOY growth in industrial production in country $i$ at time $t, I P_{W, t}^{4}$ is EOY growth in world industrial production, and $I P_{L_{i}^{\perp}, t}^{4}$ is the residual, i.e. the part of $I P_{L_{i}, t}^{4}$ that is orthogonal to $I P_{W, t}^{4}$. As the next step, we then use $I P_{L_{i}^{\perp}, t}^{4}$ (lagged) as the explanatory variable in our predictive regressions for one-year ahead real individual-country returns $\left(R_{i, t+1}\right)$, i.e. run the regression:

$$
R_{i, t+1}=\alpha+\beta I P_{L_{i}^{\perp}, t}^{4}+\varepsilon_{t+1}
$$

The results are in the $I P_{L^{\perp}}^{4}$ columns in Table 6 . The results show that there is no significant explanatory power left in local EOY growth rates when adjusted for global growth.

One reason why we gain more predictive power by using global EOY economic growth when predicting local-country returns is that local variables contain idiosyncratic noise that may not be useful for predicting returns. Global growth rates, on the other hand, contain the systematic information about the business cycle that is important for returns. For instance, $55 \%$ of the variation in growth rates across countries can be explained by a first principal component. This indicates that economic growth across countries to a large extent is driven by common shocks, i.e. a world business cycle, as also argued in, e.g., Kose, Otrok, and Whiteman (2003, 2008), Kose, Otrok, and Prasad (2012), Lumsdaine and Prasad (2003), and IMF (2007). The results are also related to those in Cooper and Priestley (2014) who report that a world $k / y$ ratio (the world's capital stock to output ratio) predicts returns in several individual countries, whereas local versions of the $k / y$ ratio do not.

Based on our finding that EOY global, and less so local, economic growth matters for expected returns, an interesting question is whether global EOY growth matters more for expected returns in more open economies, i.e. countries that trade more with other countries. To test this hypothesis, we split countries into two groups conditioned on trade openness. We consider three measures of trade openness: exports over GDP, imports over GDP, and the sum 
of exports and imports over GDP. Each year, we rank the twelve countries according to their trade openness in that year and sort the six most open economies into one group and the six least open economies into the other group. The sorting is dynamic such that countries can move between the two groups from year to year. For each group of countries and for each year, we calculate an equal-weighted average of real stock returns. Finally, we run our predictive regressions of returns on global EOY growth. We present the results in Table 7.

Not surprisingly, given the results in Table 6 that EOY economic growth is significant for most countries, we find in Table 7 that EOY global economic growth predicts the returns of both groups of countries. More important here, though, we also find that the influence of global EOY economic growth on returns (and the statistical evidence on this influence) is stronger for the group of more open countries. The $\beta$-coefficients are estimated to be around -3.2 (and the $t$-statistics around -3.8 and the $R^{2}$ s around $11 \%-12 \%$ ) for the group of countries with relatively low degrees of openness, whereas they are estimated to be around -4.1 (and the $t$-statistics around -4.8 and the $R^{2}$ s around $15 \%-16 \%$ ) for the group of countries with relatively high degrees of openness. In order to give some economic intuition to these numbers, recall that Table 1 showed that the standard deviation of global EOY growth is $1.95 \%$. A one standard deviation change in EOY growth thus lowers returns by $1.95 \% \cdot 3.2=6.2 \%$ in the least open economies compared to around $8 \%$, i.e. almost $33 \%$ more, in the most open economies. We conclude that expected returns in countries more dependent on international trade react stronger to movements in global EOY economic growth.

\section{Why does global economic growth at the end of the year predict returns?}

In this section, we show that EOY global economic growth is a strong business cycle indicator as it forecasts the cyclical component of global economic activity, whereas EOY global economic growth at other times of the year does not contain as much information about the future global business cycle. 
The output gap, i.e. the difference between actual and trend economic activity, is the standard measure of the cyclical component of economic activity. We use the Hodrick-Prescott (1997) filter to calculate the trend component of quarterly log GDP (or industrial production) for each of the twelve developed countries in our sample. ${ }^{10}$ We measure the cyclical component of GDP (or industrial production) by actual GDP minus trend GDP. We present results using the cyclical component of GDP in the following. Using the cyclical component of industrial production gives similar results.

Table 8, Panel A, shows results from regressions of country $i$ 's cyclical component of GDP $k$ quarters ahead on current-period EOY global growth in a panel-setting including our twelve countries. We show results for forecasting horizons running from one quarter $(k=1)$ up to three years, i.e. twelve quarters ahead $(k=12)$. The table reveals that EOY global economic growth contains special forecasting power for the future business cycle. First, an increase in EOY global economic growth leads to an increase in cyclical GDP one quarter ahead. The effect is strongly statistically significant with a $t$-statistic of 6.8 . None of the other growth rates $\left(I P^{1}, I P^{2}\right.$, and $\left.I P^{3}\right)$ contains forecasting power for next-quarter cyclical GDP. For longer forecast horizons, up to one year ahead, both $I P^{1}, I P^{3}$, and $I P^{4}$ contain forecasting power for the future path of cyclical GDP, but the forecasting power of $I P^{4}$ clearly exceeds that of $I P^{1}$ and $I P^{3}$, as $t$-statistics and $R^{2}$ s are markedly higher using $I P^{4}$. At the one-year horizon, the $R^{2}$ is $23.2 \%$ when forecasting the business cycle with $I P^{4}$ versus $2.6 \%$ when forecasting with $I P^{1}$ and $12.9 \%$ when forecasting with $I P^{3} . I P^{2}$ is insignificant.

In Panel B, we show results where we use innovations in economic growth as a predictor of the future business cycle. ${ }^{11}$ The innovations represent the surprise component of economic growth. Using innovations, we find even clearer evidence that EOY global economic growth is a particularly strong business cycle indicator. We find that innovations in $I P^{4}$ predict the future business cycle, whereas forecasting power by $I P^{1}$ disappears and that of $I P^{3}$ is reduced.

\footnotetext{
${ }^{10}$ We set the smoothing parameter in the Hodrick-Prescott procedure to 1600 , as is standard when working with quarterly data. We also extracted the cyclical component of GDP and industrial production via the quadratic trend procedure in Cooper and Priestley (2009). We find quantitatively the same results as those mentioned in the text.

${ }^{11}$ In Section 3, we mentioned that innovations in EOY global economic growth predict returns as strongly as EOY global economic growth itself.
} 
Three further aspects of these findings are worth noticing. First, EOY economic growth predicts cyclical GDP one year ahead. After one year, a new EOY global growth rate is realized. This new growth rate contains information about the following year's cyclical GDP, and the predictive power of last year's EOY global growth rate is markedly reduced. Hence, EOY global economic growth predicts the global business cycle one year ahead, like it predicts global returns one year ahead.

Second, the predictive coefficients in Table 8 are positive. A higher EOY global economic growth rate implies a better business cycle situation over the following year. Realizing that the global economy is doing better at the end of the year, and knowing that this has positive implications for the future business cycle, investors lower their required returns when investing in risky assets. This is what we find in our return-predicting regressions where the estimated negative sign on the slope coefficient implies a negative relation between EOY economic growth and future returns.

Third, we can visualize the findings of Table 8. Fig. 2 shows average correlations between innovations in global economic growth and output gaps in the twelve developed countries one to four quarters ahead; we average across countries, i.e. across correlations between innovations in global economic growth and the future business cycle in each of our twelve developed countries. The figure reveals that the average correlation across countries between innovations in EOY economic growth and future output gaps is around 0.4-0.5 regardless of whether we look 1, 2, 3, or 4 quarters ahead. The correlations between innovations in economic growth at other times of the year and the future business cycle are markedly lower.

Our finding that end-of-the-year economic activity is a particularly strong business cycle indicator is related to results in Wen (2002) that the fourth quarter change in output has significant business cycle implications, and to results in Barsky and Miron (1989), Beaulieu and Miron (1992), Beaulieu, MacKie-Mason, and Miron (1992) that movements in macroeconomic time series are dominated by what they call the "Christmas demand shock". The Christmas demand shock theory implies that consumers experience a taste shock around Christmas that increases their consumption above levels otherwise determined by permanent income and the 
real interest rate. These papers study seasonally unadjusted data (whereas we use seasonally adjusted data to predict returns) and find a consistent end-of-the-year boom in output across industries and countries. In relation to this literature, we show that global EOY economic growth has special implications for expected returns and that EOY economic growth contains business cycle information across many countries.

When EOY predicts returns because it is a business cycle indicator, one would expect that returns of firms affected relatively more by the business cycle would react relatively stronger to changes in EOY global economic growth. To test this hypothesis, we investigate how expected returns on cyclical and defensive stocks react to movements in EOY economic growth. We download MSCI global indexes of firms in cyclical sectors, respectively defensive sectors. MSCI defines five sectors as cyclical: Consumer Discretionary, Financials, Industrials, Technology, and Materials. The five defensive sectors are Consumer Staples, Energy, Health Care, Telecom, and Utilities. The indexes start in 1994, so we run panel forecasting regressions, with two-way clustered standard errors. Our results are as follows:

\begin{tabular}{lccc}
\hline & $\beta$ & $t$-stat & $R^{2}$ \\
Cyclical stocks & -4.3 & -5.3 & $13.1 \%$ \\
Defensive stocks & -0.5 & -0.6 & $0.2 \%$ \\
\hline
\end{tabular}

These results reveal that expected returns of firms in sectors that are affected more by changes in the global business cycle react stronger to changes in EOY global economic growth. Expected returns of firms in defensive sectors do not react.

Overall, our findings that EOY global economic growth predicts the global business cycle, predicts returns stronger in countries more dependent on global trade, and predict returns of firms more affected by the business cycle (firms in cyclical sectors) provide evidence in support of countercyclical variation in risk premia. This is so because we find that when the business cycle improves, expected returns fall, in particular in countries more dependent on international growth and in particular in sectors more affected by the business cycle. Our international results also square with the illustrative production-based model of Zhou and Zhu (2015) that in turn builds on classical production-based models, such as Cochrane (1991). Zhou and Zhu show 
that returns are determined by expected economic conditions both at home and abroad, i.e. the international business cycle. This fits with our finding: Global EOY economic growth predicts global returns and it predicts the global business cycle.

\subsection{Discount rates or cash-flows?}

A positive change in global economic growth at the end of the year indicates an improvement of the future business cycle and a reduction in expected returns. But do expected returns move because the market has adjusted its expectations of future discount rates or its expectations of future cash-flows? Given that EOY global economic growth predicts returns across a wide spectrum of asset classes, it seems at the onset intuitively more plausible that expected returns move because discount rates move; a change in global discount rates could move global equity, FX, and commodity markets, whereas it seems less clear how a movement in expected cashflows can move such different markets simultaneously. Without empirical evidence, though, we do not know whether the predictive ability of EOY global economic growth comes from the cash-flow or discount-rate channel.

In order to investigate which of the two channels is at work, we follow the approach of Cochrane (2011), Huang, Jiang, Tu, and Zhou (2015a, 2015b) and Bakshi, Panayotov, and Skoulakis (2014). They regress, respectively, dividend growth and the dividend-price ratio on the predictive variable and lagged values of dividend growth and the dividend price ratio. In our case, the regressions take the form:

$$
y_{t+1}=\alpha+\beta I P_{t}^{4}+\theta d p_{t}+\gamma d g_{t}+\varepsilon_{t+1}
$$

where $y_{t+1}$ is either the log dividend-price ratio, $d p_{t+1}$, or the log dividend growth rate, $d g_{t+1}$. The intuition behind this regression is as follows: From Campbell and Shiller (1998), we know that - up to an approximation constant - the following relation holds per construction:

$$
d p_{t}=r_{t+1}-d g_{t+1}+\rho d p_{t+1}
$$


where $r_{t+1}$ refers to log-returns. Hence, if a variable predicts $r_{t+1}$, it must also predict $d g_{t+1}$ and/or $d p_{t+1}$ in order for the relation to hold. When dividend growth proxies for cash-flow growth (Cochrane, 2011), no predictability of $d g_{t+1}$ implies that $d p_{t+1}$ moves because changes in discount rates make stock prices move.

We present the results from estimations of Eq. (5) in Table 9 using dividend growth and the dividend-price ratio on the world market portfolio, the European portfolio, the EAFA portfolio, and the Pacific portfolio. We know from Table 2 that EOY growth predicts returns on these portfolios. Table 9 shows that global EOY economic growth predicts the future dividend-price ratio, whereas there is no evidence that it predicts future dividend growth rates. This finding is consistent across portfolios. The sign to the dividend-price ratio coefficient is positive, i.e. we forecast a higher dividend-price ratio if $I P_{t}^{4}$ increases. Given that dividends do not move when $I P_{t}^{4}$ moves, as Table 9 shows, the upward lift in the dividend-price ratio comes from a lower price in period $t+1$, consistent with our finding that $I P_{t}^{4}$ negatively forecasts future returns. When dividend growth, and thus cash-flows, do not move, the change in the dividend-price ratio comes from a change in discount rates that makes the stock price move. In summary, a positive change in global EOY economic growth positively predicts the future business cycle which in turn causes discount rates to move, pushing down the expected price and consequently expected returns.

\section{Timing of global cultural and institutional events}

Jagannathan and Wang (2007), Da, Yang, and Yun (2014), and Møller and Rangvid (2015) argue that investors are more likely to make investment and saving decisions at the turn of the year where cultural/religious (Christmas and New Year) and institutional (end of tax year and payout of bonuses) activities are concentrated in many countries. In this paper, we provide evidence that there is a good reason for taking EOY economic growth into account when making portfolio decisions: It contains information about the future business cycle and returns. When EOY global economic growth is high, it signals an improvement in the business cycle. Investors base their decisions on this information, and expected returns are adjusted accordingly. 
With international data, we can examine whether variation across countries in the timing of cultural and institutional activities have consequences for the relation between economic growth and expected returns. For instance, the personal-income tax year ends at the end of the calendar year in most countries. However, in Hong Kong and India, it ends in March, while it ends in April in the UK and in June in Australia. If investors are particularly attentive to their portfolios at the turn of the tax year when they calculate their total tax-year income statements (Jagannathan and Wang, 2007), and investors take recent economic performance into account when forming portfolios (Møller and Rangvid, 2015), one might expect that the relation between economic growth and expected returns is stronger after the first quarter in India and Hong Kong and after the second quarter in Australia and UK. ${ }^{12}$

Likewise, most countries celebrate New Year at the end of the calendar year. However, many Asian countries celebrate the Chinese New Year which typically takes place in January or February. If investors are particular attentive to their portfolios around New Year and consider recent economic activity when evaluating their portfolios, we would expect a stronger relation between economic growth and expected returns after the first quarter in Asian countries. In Thailand, they celebrate New Year in April (the Songkran festival), i.e. if New Year is a time for reflection and evaluation of financial portfolios, we should see a stronger effect from economic growth to expected returns after the second quarter in Thailand.

Table 3 showed results from return-predicting regressions for the individual countries in our sample. The main conclusion is that the relation between economic growth and expected returns is clearly strongest at the end of the calendar year. In those cases where there is also a relation between, e.g., first-quarter economic growth and subsequent returns, this is due to correlation between fourth and first quarter economic growth, as mentioned in Section 3.1 and explained further in Section 7.

Our overall interpretation of these results is that the EOY effect is strong and robust across countries. Even in countries where local cultural and institutional events are not concentrated at the end of the calendar year, it is still economic activity at the end of the year that predicts

\footnotetext{
${ }^{12}$ Jagannathan et al. (2012) examine the end of the tax year in Japan, the UK, and the US and its implications for the consumption CAPM.
} 
returns. This is because EOY global economic growth forecasts the future global business cycle, whereas economic activity at other times of the year does not contain as strong information about the future business cycle. So, even if some investors in a country where the tax year ends in, e.g., April concentrate their portfolio adjustments at that point in time, they do not particularly look at economic activity at that point in time, as it does not contain much information about the future business cycle. EOY global economic growth, on the other hand, contains predictive information about the global business cycle and returns around the world.

\section{Robustness tests}

We have conducted a large number of robustness tests to verify that our results are robust. A full account of the results of these tests can be found in the Internet Appendix. Here, we briefly mention the main results.

- Data on industrial production are published with a lag. To take publication lags into account, we forecasts returns starting one quarter ahead, e.g., returns from April 1 through March 31 (next year) when forecasting with $I P^{4}$, etc. Results are robust.

- We use monthly growth rates to predict returns. Within the fourth quarter, global December growth predicts excess returns on the world portfolio stronger than November and October growth. Growth during other months does not predict returns.

- We predict calendar year returns using Q1, Q2, Q3, and Q4 growth, April 1-March 30 (next year) returns using Q1, Q2, Q3, and Q4 growth, etc. Results are robust

- EOY global economic growth also predicts returns on global value and growth portfolios.

- In some cases, $I P^{1}$ is significant in Table 3 . We use the part of $I P^{1}$ that is uncorrelated with $I P^{4}$ to predict returns in those countries where $I P^{1}$ is significant on its own. We find that there is no single case where the part of $I P^{1}$ that is uncorrelated with $I P^{4}$ significantly predicts returns. 
- We calculate global economic growth in different ways. E.g., we consider GDP-weighted industrial production growth rates or the first principal component from the twelve individual-country industrial production growth rates. Instead of end-of-quarter values, we also use the average level of industrial production during a quarter, i.e. $I P^{4}$ calculated as $\left(I P^{D e c}+I P^{N o v}+I P^{O c t}\right) /\left(I P^{S e p}+I P^{A u g}+I P^{J u l y}\right)$ where $I P^{D e c}$ is the level of industrial production in December, $I P^{N o v}$ the level in November, etc. Results are robust.

- We consider fourth-quarter to fourth-quarter (Q4-Q4) global economic growth (as in Jagannathan and Wang, 2007) or December-December global economic growth as alternative measures of end-of-the-year global economic growth. Similar to results in Møller and Rangvid (2015) for the US, we find that the Q3-Q4 global economic growth rate that we use in this paper contains a considerably higher amount of predictive power.

- We check what happens if we use GDP growth instead of growth in industrial production. We find strong predictability by GDP growth at the end of the year and no predictability by GDP growth during the second and the third quarter. We find GDP growth during the first quarter to be significant, but when we use the part of GDP growth during the first quarter that is independent of GDP growth during the fourth quarter of the previous year, $G D P^{1}$ is no longer significant.

- Results are robust during subsamples.

- Henkel, Martin, and Nardari (2011) and Rapach, Strauss, and Zhou (2010) show that forecasting power of, e.g., the dividend-yield is concentrated to recessions. We find strong predictive power of $I P^{4}$ both in expansions and recessions.

- Classical results in Goetzmann and Jorion (1993), Nelson and Kim (1993), and Kothari and Shanken (1997) demonstrate that slope coefficients in predictive regressions can be biased in small samples. We do a comprehensive residual-based bootstrap analysis to investigate this. We also do a parametric bootstrap to check robustness. We verify that our results are not due to a small-sample bias in the estimated coefficients.

- Results for individual countries are robust to using returns in local currencies or USD. 
In total, these checks and others make us conclude that our results are robust and statistically strong.

\section{Conclusion}

We have shown that global economic activity at the end of the year strongly predicts returns around the world. We find this for individual-country returns, regional returns, returns on the world market portfolio, FX returns, and commodity returns. We have also shown that EOY global economic activity predicts international stock returns both in-sample and out-of-sample. Global economic growth at other times of the year does not predict international returns. The main explanation for our results is that EOY global economic growth also forecasts the global business cycle. When EOY global economic growth is high, the future global business cycle improves. Investors react to the change in expected global business conditions that a change in EOY global economic growth predicts by adjusting the rates at which they discount future cash-flows. This causes expected returns on risky assets around the world to change.

The results provided in this paper contribute to a new literature that documents that economic activity at the end of the year contains particularly interesting information about expected returns. We predict that this literature will develop further and generate new exiting insights about the influence of end-of-the-year economic activity on asset markets. We attempt to contribute to this research agenda. 


\section{References}

Bakshi, G., Panayotov, G., Skoulakis, G., 2014. The Baltic Dry Index as a predictor of global stock returns, commodity returns, and global economic activity. Manuscript. University of Maryland.

Barsky, R., Miron, J., 1989. The seasonal cycle and the business cycle. Journal of Political Economy 97, 503-534.

Beaulieu, J., MacKie-Mason, J., Miron, J., 1992. Why do countries and industries with large seasonal cycles also have large business cycles? Quarterly Journal of Economics 107, 621-656.

Beaulieu, J., Miron, J., 1992. A cross-country comparison of seasonal cycles and business cycles. Economic Journal 102, 772-788.

Campbell, J.Y., 1991. A variance decomposition for stock returns. Economic Journal 101, 157179.

Campbell, J., Shiller, R., 1988. The dividend-price ratio and expectations of future dividends and discount factors. Review of Financial Studies 1, 195-208.

Campbell, J., Thompson, S., 2008. Predicting excess stock returns out of sample: Can anything beat the historical average? Review of Financial Studies 21, 1509-1531.

Clark, T. E. and McCracken, M., 2011. Testing for unconditional predictive ability. In M. Clements and D. Hendry (Eds.), Oxford Handbook of Economic Forecasting. Oxford University Press.

Clark, T., West, K., 2007. Approximately normal tests for equal predictive accuracy in nested models. Journal of Econometrics 138, 291-311.

Cochrane, J.H., 1991. Production-based asset pricing and the link between stock returns and economic fluctuations. Journal of Finance 46, 207-234

Cochrane, J.H., 2011. Discount rates. Journal of Finance 66, 1047-1108.

Cooper, I., Priestley, R., 2009. Time-varying risk premiums and the output gap. Review of Financial Studies 22, 2801-2833.

Cooper, I., Priestley, R., 2014. The world business cycle and expected returns. Review of Finance 17, 1029-1064.

Da, Z., Huang, D., Yun, H., 2015. Industrial electricity usage and stock returns. Forthcoming, Journal of Financial and Quantitative Analysis.

Da, Z., Yang, W., Yun, H., 2014. Houshold production and asset prices. Forthcoming, Management Science. 
Diebold, F.X., Mariano, R.S., 1995. Comparing Predictive Accuracy. Journal of Business and Economic Statistics 13, 253-263.

Fama, E., Schwert, W., 1977. Asset returns and inflation. Journal of Financial Economics 5, $115-146$.

Goetzmann, W. N., Jorion, P., 1993. Testing the predictive power of dividend yields. Journal of Finance 48, 663-679.

Goyal, A., Welch, I., 2008. A comprehensive look at the empirical performance of equity premium prediction. Review of Financial Studies 21, 1455-1508.

Hansen, L.P., Hodrick, R.J., 1980. Forward exchange rates as optimal predictors of future spot rates: An econometric analysis. Journal of Political Economy 88, 829-853

Henkel, S.J., Martin, J.S., Nardari, F., 2011. Time-varying short-horizon predictability. Journal of Financial Economics 99, 560-580.

Hodrick, R.J., 1992. Dividend yields and expected stock returns: Alternative procedures for inference and measurement. Review of Financial Studies 5, 357-386.

Hodrick, R., Prescott, E., 1997. Postwar U.S. business cycles: An empirical investigation. Journal of Money, Credit, and Banking 29, 1-16.

Huang, D., Jiang, F., Tu, J., Zhou, G., 2015a. Investment sentiment aligned: A powerful predictor of stock returns. Review of Financial Studies 28, 791-837.

Huang, D., Jiang, F., Tu, J., Zhou, G., 2015b. Forecasting stock returns during good and bad times. Manuscrip, Washington University in St. Louis.

IMF, 2007. The changing dynamics of the global business cycle. Chap. 5 in World Economic Outlook, October 2007.

Jagannathan, R., Wang, Y., 2007. Lazy investors, discretionary consumption, and the crosssection of stock returns. Journal of Finance 62, 1623-1661.

Jagannathan, R., Marakani, S., Takehara, H, Wang, Y., 2012. Calendar cycles, infrequent decisions, and the cross section of stock returns. Management Science 58, 507-522.

Kothari, S.P., Shanken, J., 1997. Book-to-market, dividend yield, and expected market returns: A time-series analysis. Journal of Financial Economics 44, 169-203.

Kose, M.A., Otrok, C., Whiteman, C.H., 2003. International business cycles: World, region, and country-specific factors. American Economic Review 93, 1216-1239.

Kose, M.A., Otrok, C., Whiteman, C.H., 2008. Understanding the evolution of world business cycles. Journal of International Economics 75, 110-30. 
Kose, M.A., Otrok, C., Prasad, E., 2012. Global business cycles: Convergence or decoupling? International Economic Review 53, 511-538.

Lettau, M., Ludvigson, S., 2001. Consumption, aggregate wealth, and expected returns. Journal of Finance 55, 815-849.

Lumsdaine, R. L., Prasad, E. S., 2003. Identifying the common component in international economic fluctuations. Economic Journal 113, 101-27.

Lustig, H., Roussanov, N., Verdelhan, A., 2011. Common risk factors in currency markets. Review of Financial Studies 24, 3731-3777.

Mehra, R., 2008. Handbook of the Equity Risk Premium, North Holland, Amsterdam.

Møller, S., Rangvid, J., 2015. End-of-the-year economic growth and expected returns. Journal of Financial Economics 115, 136-154.

Nelson, C., Kim, M., 1993. Predictable stock returns: The role of small samples. Journal of Finance 48, 641-661.

Newey, W., West, K., 1987. A simple, positive semidefinite, heteroskedasticity and autocorrelation consistent covariance matrix. Econometrica 55, 703-708.

Newey, W., West, K., 1994. Automatic lag selection in covariance matrix estimation. Review of Economic Studies 61, 631-654.

Rapach, D., Rangvid, J., Wohar, M., 2005. Macro variables and international stock return predictability. International Journal of Forecasting 21, 137-166.

Rapach, D.E., Strauss, J.K., Zhou, G., 2010. Out-of-sample equity premium prediction: Combination forecasts and links to the real economy. Review of Financial Studies 23, 821-868.

Stambaugh, R., 1999. Predictive regressions. Journal of Financial Economics 54, 375-421.

Thompson, S., 2011. Simple formulas for standard errors that cluster by both firm and time. Journal of Financal Economics 99, 1-10.

Wen, Y., 2002. The business cycle effect of Christmas. Journal of Monetary Economics 49, 1289-1314.

Zhou, G., Zhu, X., 2015. Bond return predictability and macroeconomy: The international link. Manuscrip, Washington University in St. Louis. 
Table 1. Summary statistics.

\begin{tabular}{|c|c|c|c|c|c|c|c|c|}
\hline \multicolumn{9}{|c|}{ Panel A: Predictive variables } \\
\hline & \multicolumn{4}{|c|}{ Industrial production growth } & \multicolumn{4}{|c|}{ Benchmark variables } \\
\hline & $I P^{1}$ & $I P^{2}$ & $I P^{3}$ & $I P^{4}$ & DP & CAY & TBL & INF \\
\hline AVG & $0.31 \%$ & $0.56 \%$ & $0.48 \%$ & $0.47 \%$ & $2.88 \%$ & 0.00 & $5.05 \%$ & $4.35 \%$ \\
\hline $\mathrm{SD}$ & $1.50 \%$ & $1.08 \%$ & $1.05 \%$ & $1.95 \%$ & $1.04 \%$ & $2.42 \%$ & $3.39 \%$ & $3.36 \%$ \\
\hline AR1 & -0.23 & -0.22 & -0.13 & -0.17 & 0.92 & 0.87 & 0.88 & 0.91 \\
\hline \multicolumn{9}{|c|}{ Panel B: Returns } \\
\hline & World & Europe & EAFA & Pacific & Australia & Belgium & Canada & France \\
\hline AVG & $6.99 \%$ & $8.42 \%$ & $7.90 \%$ & $8.91 \%$ & $6.65 \%$ & $9.83 \%$ & $6.94 \%$ & $8.32 \%$ \\
\hline SD & $18.07 \%$ & $21.75 \%$ & $22.15 \%$ & $29.61 \%$ & $22.34 \%$ & $25.68 \%$ & $17.01 \%$ & $25.07 \%$ \\
\hline AR1 & 0.00 & -0.03 & 0.08 & 0.08 & -0.17 & -0.02 & -0.05 & -0.04 \\
\hline & Germany & Italy & Japan & Netherl. & Sweden & Switzerl. & UK & US \\
\hline AVG & $8.18 \%$ & $4.68 \%$ & $7.17 \%$ & $9.32 \%$ & $13.21 \%$ & $7.78 \%$ & $8.02 \%$ & $7.27 \%$ \\
\hline SD & $25.66 \%$ & $29.50 \%$ & $28.21 \%$ & $22.60 \%$ & $29.31 \%$ & $22.76 \%$ & $23.37 \%$ & $17.87 \%$ \\
\hline AR1 & -0.07 & 0.18 & 0.01 & 0.03 & 0.03 & -0.01 & -0.25 & 0.05 \\
\hline & FX & Commod. & & & & & & \\
\hline AVG & $2.20 \%$ & $0.52 \%$ & & & & & & \\
\hline $\mathrm{SD}$ & $7.94 \%$ & $20.00 \%$ & & & & & & \\
\hline AR1 & 0.00 & 0.19 & & & & & & \\
\hline
\end{tabular}

The table reports averages (AVG), standard deviations (SD), and first order autocorrelations (AR1) for the predictive variables and returns. We compute stock returns based on the MSCI total return indexes. The global/regional returns (World, Europe, EAFA, and Pacific) are denoted in US dollars, and we use the US inflation rate to obtain real returns. The country returns are in local currency, and we use local inflation rates to obtain real returns. The inflation rates are computed using the consumer price index (all items) available from OECD. We also report excess returns on foreign exchange and commodities (denoted in US dollars). All returns are measured over the calendar year. We compute global industrial production growth using the cross-country average for the twelve countries in the sample (data are from the OECD). $I P^{1}, I P^{2}, I P^{3}$, and $I P^{4}$ denote the first, second, third, and fourth quarter growth rates. DP is the dividend-price ratio on the world stock market index. It is computed based on the MSCI World price indexes with and without dividend reinvestment. CAY is the US consumption-wealth ratio of Lettau and Ludvigson (2001). TBL is the world risk free rate of return proxied by a short US Tbill rate. INF is the global inflation rate computed using the cross-country average. The benchmark variables are measured annually. For stock returns and the predictive variables, the sample period is 1970 to 2013. 
Table 2. Forecasting international stock returns.

\begin{tabular}{|c|c|c|c|c|c|c|c|c|c|c|c|c|}
\hline & \multicolumn{3}{|c|}{$I P^{1}$} & \multicolumn{3}{|c|}{$I P^{2}$} & \multicolumn{3}{|c|}{$I P^{3}$} & \multicolumn{3}{|c|}{$I P^{4}$} \\
\hline & $\beta$ & $t$ & $R^{2}$ & $\beta$ & $t$ & $R^{2}$ & $\beta$ & $t$ & $R^{2}$ & $\beta$ & $t$ & $R^{2}$ \\
\hline \multicolumn{13}{|c|}{ Panel A: Predicting with economic growth } \\
\hline$\underline{\text { Returns }}$ & \multicolumn{12}{|c|}{ World } \\
\hline Nominal & -1.9 & -0.9 & $2.3 \%$ & -1.1 & -0.5 & $0.5 \%$ & -1.1 & -0.4 & $0.3 \%$ & -3.1 & -4.3 & $11.3 \%$ \\
\hline Excess & -2.2 & -1.0 & $2.9 \%$ & -1.0 & -0.5 & $0.4 \%$ & -1.1 & -0.4 & $0.4 \%$ & -3.6 & -5.3 & $14.5 \%$ \\
\hline \multirow[t]{2}{*}{ Real } & -1.9 & -0.9 & $2.2 \%$ & -1.6 & -0.7 & $0.9 \%$ & -1.3 & -0.5 & $0.5 \%$ & -3.3 & -4.4 & $12.6 \%$ \\
\hline & \multicolumn{12}{|c|}{ Europe } \\
\hline Nominal & -1.7 & -0.7 & $1.2 \%$ & 3.6 & 1.4 & $3.0 \%$ & 0.6 & 0.2 & $0.1 \%$ & -3.7 & -4.9 & $11.0 \%$ \\
\hline Excess & -2.0 & -1.0 & $2.9 \%$ & 3.6 & 1.3 & $3.1 \%$ & 0.5 & 0.2 & $0.1 \%$ & -4.2 & -6.5 & $13.7 \%$ \\
\hline \multirow[t]{2}{*}{ Real } & -1.7 & -0.6 & $1.1 \%$ & 2.9 & 1.1 & $2.0 \%$ & 0.3 & 0.1 & $0.0 \%$ & -3.8 & -5.7 & $12.1 \%$ \\
\hline & \multicolumn{12}{|c|}{ Europe, Australasia and Far East } \\
\hline Nominal & -0.9 & -0.3 & $0.3 \%$ & 0.4 & 0.2 & $0.0 \%$ & -1.1 & -0.4 & $0.2 \%$ & -3.9 & -4.3 & $12.1 \%$ \\
\hline Excess & -1.1 & -0.4 & $0.5 \%$ & 0.5 & 0.2 & $0.1 \%$ & -1.2 & -0.4 & $0.3 \%$ & -4.4 & -5.1 & $14.8 \%$ \\
\hline \multirow[t]{2}{*}{ Real } & -0.9 & -0.3 & $0.3 \%$ & -0.1 & -0.1 & $0.0 \%$ & -1.4 & -0.5 & $0.4 \%$ & -4.1 & -4.3 & $13.1 \%$ \\
\hline & \multicolumn{12}{|c|}{ Pacific } \\
\hline Nominal & 0.7 & 0.2 & $0.1 \%$ & -2.9 & -1.0 & $1.3 \%$ & -2.9 & -1.1 & $1.0 \%$ & -4.1 & -2.5 & $7.3 \%$ \\
\hline Excess & 0.4 & 0.1 & $0.0 \%$ & -2.8 & -1.0 & $1.2 \%$ & -3.0 & -1.0 & $1.1 \%$ & -4.6 & -2.8 & $8.9 \%$ \\
\hline \multirow[t]{2}{*}{ Real } & 0.7 & 0.2 & $0.1 \%$ & -3.2 & -1.2 & $1.7 \%$ & -3.2 & -1.1 & $1.3 \%$ & -4.3 & -2.5 & $8.0 \%$ \\
\hline & \multicolumn{12}{|c|}{ All returns: Panel regressions } \\
\hline Nominal & -1.1 & -0.5 & $0.4 \%$ & 0.1 & 0.0 & $0.0 \%$ & -1.4 & -0.6 & $0.4 \%$ & -3.7 & -4.7 & $9.5 \%$ \\
\hline Excess & -1.4 & -0.5 & $0.7 \%$ & 0.1 & 0.1 & $0.0 \%$ & -1.5 & -0.6 & $0.5 \%$ & -4.2 & -5.5 & $11.8 \%$ \\
\hline Real & -1.1 & -0.4 & $0.4 \%$ & -0.4 & -0.2 & $0.0 \%$ & -1.7 & -0.7 & $0.6 \%$ & -3.8 & -4.7 & $10.4 \%$ \\
\hline \multicolumn{13}{|c|}{ Panel B: Predicting calendar-year return on the world market portfolio with benchmark variables } \\
\hline & \multicolumn{3}{|c|}{ DP } & \multicolumn{3}{|c|}{ CAY } & \multicolumn{3}{|c|}{ TBL } & \multicolumn{3}{|c|}{ INF } \\
\hline Nominal & 4.5 & 1.9 & $6.8 \%$ & 1.7 & 1.6 & $5.1 \%$ & 0.0 & 0.1 & $0.0 \%$ & 0.0 & 0.0 & $0.0 \%$ \\
\hline Excess & 2.4 & 0.9 & $1.9 \%$ & 1.5 & 1.3 & $3.7 \%$ & -1.1 & -1.7 & $3.6 \%$ & -0.7 & -0.9 & $1.6 \%$ \\
\hline Real & 2.7 & 1.1 & $2.4 \%$ & 2.0 & 1.8 & $6.7 \%$ & -0.5 & -0.8 & $0.8 \%$ & -0.6 & -0.8 & $1.2 \%$ \\
\hline
\end{tabular}

In Panel A, we show results from regressions of one-year ahead returns from the world-market portfolio and regional portfolios on the lag of quarterly growth rates in global industrial production:

$$
R_{t+1}=\alpha+\beta I P_{t}^{i}+\varepsilon_{t+1}
$$

When $i=1$, we use the Q1 growth rate in industrial production as regressor, and $R_{t+1}$ is measured from the beginning of April to the end of March next year. When $i=2$, we use the Q2 growth rate in industrial production as regressor, and $R_{t+1}$ is measured from the beginning 
of July to the end of June next year. When $i=3$, we use the Q3 growth rate in industrial production as regressor, and $R_{t+1}$ is measured from the beginning of September to the end of August next year. Finally, when $i=4$, we use the $\mathrm{Q} 4$ growth rate in industrial production as regressor, and $R_{t+1}$ is measured from the beginning of January to the end of December. In panel $\mathrm{B}$, we show results from regressions of one-year ahead returns on lagged benchmark variables. Returns are measured from the beginning of January to the end of December, like when predicting with $I P^{4}$. The table reports slope estimates, Newey and West (1987) corrected $t$-statistics (one lag), and $R^{2}$ statistics. For the panel regressions where we include all returns, we use two-way clustered (clustered by year and by country) standard errors as in Thompson (2011). Bold font indicates statistical significance at the $5 \%$ level. The sample period is $1970-$ 2013. 
Table 3. Forecasting real country returns using global economic growth.

\begin{tabular}{|c|c|c|c|c|c|c|c|c|c|c|c|c|c|}
\hline & \multirow{2}{*}{$\begin{array}{r}\text { Sample } \\
\text { begins }\end{array}$} & \multicolumn{3}{|c|}{$I P^{1}$} & \multicolumn{3}{|c|}{$I P^{2}$} & \multicolumn{3}{|c|}{$I P^{3}$} & \multicolumn{3}{|c|}{$I P^{4}$} \\
\hline & & $\beta$ & $t$ & $R^{2}$ & $\beta$ & $t$ & $R^{2}$ & $\beta$ & $t$ & $R^{2}$ & $\beta$ & $t$ & $R^{2}$ \\
\hline \multicolumn{14}{|c|}{ Panel A: Developed countries } \\
\hline Australia & 1970 & -3.1 & $\overline{-2.7}$ & $5.9 \%$ & -0.7 & -0.2 & $0.2 \%$ & -3.7 & -0.8 & $2.4 \%$ & -4.9 & -3.8 & $18.8 \%$ \\
\hline Belgium & 1970 & -2.2 & -0.8 & $1.9 \%$ & 2.0 & 0.7 & $1.0 \%$ & 1.6 & 0.6 & $0.5 \%$ & -3.2 & -2.2 & $5.9 \%$ \\
\hline Canada & 1970 & -1.5 & -1.0 & $1.3 \%$ & -0.8 & -0.3 & $0.2 \%$ & 2.0 & 0.7 & $1.0 \%$ & -2.5 & -2.8 & $8.0 \%$ \\
\hline France & 1970 & -2.0 & -0.9 & $1.4 \%$ & 2.9 & 0.8 & $2.0 \%$ & -2.6 & -0.7 & $1.1 \%$ & -3.8 & -3.2 & $9.0 \%$ \\
\hline Germany & 1970 & -2.5 & -1.3 & $1.8 \%$ & 0.3 & 0.1 & $0.0 \%$ & 0.4 & 0.1 & $0.0 \%$ & -3.5 & -2.7 & $7.5 \%$ \\
\hline Italy & 1970 & 0.7 & 0.2 & $0.1 \%$ & -4.9 & -0.9 & $2.9 \%$ & 1.3 & 0.4 & $0.2 \%$ & -1.7 & -1.5 & $1.3 \%$ \\
\hline Japan & 1970 & 0.4 & 0.1 & $0.1 \%$ & -4.7 & -2.0 & $4.8 \%$ & -2.3 & -0.8 & $1.0 \%$ & -3.1 & -1.8 & $4.7 \%$ \\
\hline Netherl. & 1970 & -4.9 & -2.3 & $7.8 \%$ & -2.8 & -1.0 & $1.9 \%$ & -1.0 & -0.4 & $0.2 \%$ & -4.6 & -4.1 & $15.9 \%$ \\
\hline Sweden & 1970 & -3.8 & -1.4 & $2.9 \%$ & -9.3 & -2.2 & $9.3 \%$ & -8.0 & -1.7 & $5.9 \%$ & -4.9 & -3.6 & $11.0 \%$ \\
\hline Switzerl. & 1970 & -2.6 & -1.7 & $3.3 \%$ & -0.8 & -0.4 & $0.2 \%$ & 0.1 & 0.1 & $0.0 \%$ & -3.7 & -3.1 & $10.2 \%$ \\
\hline UK & 1970 & -3.5 & -2.5 & $7.9 \%$ & -2.2 & -0.9 & $1.8 \%$ & -3.3 & -0.8 & $2.5 \%$ & -5.8 & -2.1 & $23.5 \%$ \\
\hline US & 1970 & -2.8 & -1.8 & $5.0 \%$ & -2.4 & -0.9 & $2.0 \%$ & -1.3 & -0.5 & $0.5 \%$ & -2.5 & -3.3 & $7.5 \%$ \\
\hline All & 1970 & -2.4 & -1.2 & $2.0 \%$ & -1.9 & -0.8 & $0.8 \%$ & -1.6 & -0.6 & $0.5 \%$ & -3.6 & -4.6 & $8.6 \%$ \\
\hline \multicolumn{14}{|c|}{ Panel B: Emerging countries } \\
\hline \multicolumn{14}{|l|}{$\underline{\underline{\text { Asia }}}$} \\
\hline Hong K. & 1982 & -2.6 & -0.9 & $2.4 \%$ & -4.9 & -0.8 & $1.6 \%$ & -1.3 & -0.3 & $0.2 \%$ & -5.4 & -2.7 & $8.6 \%$ \\
\hline India & 1993 & -5.2 & -2.1 & $7.0 \%$ & -8.5 & -1.4 & $8.2 \%$ & -8.3 & -1.8 & $7.1 \%$ & -8.4 & -3.6 & $20.5 \%$ \\
\hline Indonesia & 1988 & -5.2 & -1.3 & $1.8 \%$ & 6.7 & 0.6 & $1.3 \%$ & 1.5 & 0.1 & $0.0 \%$ & -8.9 & -3.1 & $13.7 \%$ \\
\hline Malaysia & 1988 & -2.3 & -0.9 & $1.4 \%$ & -8.9 & -1.4 & $7.1 \%$ & -7.8 & -1.6 & $6.0 \%$ & -5.6 & -2.5 & $10.6 \%$ \\
\hline Philippin. & 1988 & -5.3 & -4.2 & $8.7 \%$ & -2.8 & -0.5 & $0.1 \%$ & -3.1 & -0.4 & $0.7 \%$ & -8.0 & -2.6 & $13.4 \%$ \\
\hline Korea & 1988 & -3.2 & -1.2 & $2.4 \%$ & -10.2 & -1.2 & $2.5 \%$ & -10.7 & -1.4 & $4.3 \%$ & -6.3 & -4.0 & $11.9 \%$ \\
\hline Singapore & 1970 & -3.5 & -1.2 & $2.4 \%$ & -4.5 & -1.8 & $4.5 \%$ & -6.0 & -1.8 & $3.7 \%$ & -9.1 & -5.0 & $16.7 \%$ \\
\hline Taiwan & 1988 & -2.8 & -1.2 & $1.9 \%$ & -4.7 & -0.7 & $1.9 \%$ & -2.4 & -0.5 & $0.4 \%$ & -9.9 & -4.6 & $25.7 \%$ \\
\hline Thailand & 1988 & -7.3 & -3.1 & $12.6 \%$ & -5.9 & -0.8 & $1.6 \%$ & -6.9 & -1.1 & $3.5 \%$ & -9.3 & -2.7 & $13.8 \%$ \\
\hline \multicolumn{14}{|c|}{ Eastern Europe } \\
\hline$\overline{\text { Czech R. }}$ & 1995 & -0.8 & -0.2 & $0.0 \%$ & 4.6 & 0.8 & $2.7 \%$ & -9.2 & -1.3 & $7.5 \%$ & -2.6 & -2.0 & $4.1 \%$ \\
\hline Hungary & 1995 & -11.9 & -3.1 & $21.8 \%$ & -1.3 & -0.2 & $0.1 \%$ & 1.6 & 0.3 & $0.1 \%$ & -6.4 & -5.0 & $13.0 \%$ \\
\hline Poland & 1993 & -6.1 & -1.9 & $0.6 \%$ & -2.0 & -0.3 & $0.5 \%$ & -4.0 & -0.7 & $2.2 \%$ & -4.4 & -3.9 & $8.8 \%$ \\
\hline Russia & 1995 & -5.9 & -2.3 & $1.9 \%$ & -0.1 & -0.0 & $0.0 \%$ & 5.4 & 0.6 & $0.8 \%$ & -7.8 & -4.7 & $12.5 \%$ \\
\hline \multicolumn{14}{|c|}{ Latin America } \\
\hline Argentina & 1994 & -5.3 & -1.3 & $6.1 \%$ & 9.1 & 1.0 & $5.3 \%$ & -10.1 & -1.0 & $6.0 \%$ & -7.0 & -4.5 & $14.0 \%$ \\
\hline Brazil & 1994 & -4.5 & -2.4 & $7.5 \%$ & -3.7 & -0.4 & $1.4 \%$ & -2.7 & -0.5 & $0.6 \%$ & -7.7 & -3.3 & $15.3 \%$ \\
\hline Chile & 1994 & -2.8 & -1.4 & $7.0 \%$ & 2.8 & 0.6 & $1.5 \%$ & -0.9 & -0.2 & $0.1 \%$ & -5.5 & -4.8 & $20.2 \%$ \\
\hline Mexico & 1994 & -5.9 & -3.6 & $14.2 \%$ & -0.5 & -0.1 & $0.0 \%$ & -3.9 & -0.9 & $2.4 \%$ & -4.7 & -3.6 & $13.3 \%$ \\
\hline Peru & 1994 & -4.0 & -2.3 & $4.4 \%$ & 4.5 & 0.5 & $1.4 \%$ & -6.9 & -1.2 & $3.1 \%$ & -5.7 & -2.0 & $8.7 \%$ \\
\hline
\end{tabular}

We regress one-year ahead real country returns on the lag of quarterly growth rates in global industrial production. The returns are in local currency. We use local inflation rates to compute real returns. For the developed countries, the sample period is 1970-2013. For the emerging countries, the first year of the sample period differs from country to country. Bold font indicates statistical significance at the $5 \%$ level. 
Table 4. Forecasting FX and commodity returns.

\begin{tabular}{|c|c|c|c|c|c|c|c|c|c|c|c|}
\hline \multicolumn{3}{|c|}{$I P^{1}$} & \multicolumn{3}{|c|}{$I P^{2}$} & \multicolumn{3}{|c|}{$I P^{3}$} & \multicolumn{3}{|c|}{$I P^{4}$} \\
\hline$\beta$ & $t$ & $R^{2}$ & $\beta$ & $t$ & $R^{2}$ & $\beta$ & $t$ & $R^{2}$ & $\beta$ & $t$ & $R^{2}$ \\
\hline
\end{tabular}

$\underline{\text { Panel A: FX returns }}$

\begin{tabular}{|c|c|c|c|c|c|c|c|c|c|c|c|}
\hline \multicolumn{12}{|c|}{ All countries } \\
\hline-0.3 & -0.3 & $0.2 \%$ & 0.6 & 0.2 & $0.3 \%$ & -0.8 & -0.6 & $1.2 \%$ & -1.1 & -2.7 & $6.0 \%$ \\
\hline \multicolumn{12}{|c|}{ Developed markets } \\
\hline-0.2 & -0.2 & $0.1 \%$ & 1.1 & 0.4 & $0.9 \%$ & -1.3 & -0.9 & $2.4 \%$ & -1.3 & -2.8 & $6.3 \%$ \\
\hline \multicolumn{12}{|c|}{ Emerging markets } \\
\hline-0.8 & -1.3 & $3.3 \%$ & -0.6 & -0.3 & $0.5 \%$ & -0.6 & -0.6 & $1.2 \%$ & -0.9 & -2.4 & $6.7 \%$ \\
\hline
\end{tabular}

$\underline{\text { Panel B: Commodity returns }}$

Spot price growth

\begin{tabular}{llllllllllll}
-1.0 & -0.4 & $0.8 \%$ & 3.1 & 1.0 & $3.4 \%$ & 2.8 & 1.0 & $3.5 \%$ & -5.0 & $\mathbf{- 4 . 8}$ & $23.2 \%$ \\
& & \multicolumn{8}{c}{ Spot price growth in excess of risk-free rate } \\
-1.4 & -0.5 & $1.3 \%$ & 3.7 & 1.1 & $4.1 \%$ & 3.0 & 0.9 & $3.1 \%$ & -5.6 & $\mathbf{- 5 . 0}$ & $24.6 \%$
\end{tabular}

In Panel A, we regress returns from portfolios of one-year ahead currency returns (local currencies against the US dollar) on the lag of quarterly growth rates in global industrial production. The sample period starts for most currencies around 1985 and ends in 2013. In Panel B, we regress one-year ahead spot price growth rates from an equal-weighted portfolio of 19 commodities on the lag of quarterly growth rates in global industrial production. The 19 commodities are coffee, corn, cotton, hogs, sugar, wheat, wool, aluminium, copper, gold, lead, nickel, platinum, silver, zinc, crude oil, natural gas, lumber, and fish (denoted in US dollars). The sample period is $1980-2013$. 
Table 5. Out-of-sample forecasts of returns on international stock market portfolios.

\begin{tabular}{|c|c|c|c|c|c|c|c|c|}
\hline & \multicolumn{2}{|c|}{$I P^{1}$} & \multicolumn{2}{|c|}{$I P^{2}$} & \multicolumn{2}{|c|}{$I P^{3}$} & \multicolumn{2}{|c|}{$I P^{4}$} \\
\hline \multicolumn{9}{|c|}{ Panel A: Mean Absolute Forecast Error } \\
\hline & $M A E$ & $P$-value & $M A E$ & $P$-value & $M A E$ & $P$-value & $M A E$ & $P$-value \\
\hline \multicolumn{9}{|c|}{ World and regional returns } \\
\hline World & 1.05 & 0.80 & 0.98 & 0.28 & 1.02 & 0.7 & 0.89 & 0.09 \\
\hline Europe & 1.01 & 0.63 & 1.02 & 0.92 & 1.00 & 0.48 & 0.92 & 0.07 \\
\hline EAFA & 1.03 & 0.65 & 1.00 & 0.38 & 0.99 & 0.43 & 0.87 & 0.06 \\
\hline Pacific & 1.03 & 0.71 & 1.01 & 0.61 & 1.00 & 0.45 & 0.87 & 0.01 \\
\hline \multicolumn{9}{|c|}{ Country returns } \\
\hline Australia & 1.27 & 1.00 & 0.96 & 0.08 & 0.97 & 0.26 & 0.82 & 0.06 \\
\hline Belgium & 1.07 & 0.82 & 1.01 & 0.96 & 1.00 & 0.49 & 0.95 & 0.10 \\
\hline Canada & 1.07 & 0.99 & 1.00 & 0.45 & 1.01 & 0.90 & 0.94 & 0.12 \\
\hline France & 1.03 & 0.83 & 1.01 & 0.89 & 0.95 & 0.11 & 0.92 & 0.08 \\
\hline Germany & 1.03 & 0.95 & 1.01 & 0.64 & 1.01 & 0.67 & 0.93 & 0.06 \\
\hline Italy & 1.05 & 0.75 & 0.97 & 0.18 & 1.04 & 0.83 & 1.00 & 0.56 \\
\hline Japan & 1.02 & 0.69 & 0.99 & 0.32 & 1.00 & 0.54 & 0.93 & 0.07 \\
\hline Netherlands & 1.05 & 0.89 & 1.02 & 0.66 & 0.98 & 0.34 & 0.86 & 0.03 \\
\hline Sweden & 1.06 & 0.99 & 0.97 & 0.35 & 1.02 & 0.62 & 0.92 & 0.08 \\
\hline Switzerland & 1.02 & 0.94 & 0.99 & 0.34 & 0.98 & 0.21 & 0.92 & 0.03 \\
\hline UK & 1.04 & 0.97 & 1.01 & 0.96 & 1.08 & 0.72 & 0.89 & 0.15 \\
\hline US & 1.04 & 0.87 & 1.04 & 0.79 & 1.03 & 0.92 & 0.93 & 0.14 \\
\hline
\end{tabular}

Panel B: Mean Squared Forecast Error

\begin{tabular}{|c|c|c|c|c|c|c|c|c|c|}
\hline & $M S E$ & $P$-value & $M S E$ & $P$-value & $M S E$ & $P$-value & $M S E$ & $P$-value & $R_{\mathrm{OOS}}^{2}$ \\
\hline \multicolumn{10}{|c|}{ World and regional returns } \\
\hline World & 1.03 & 0.68 & 0.98 & 0.33 & 1.03 & 0.75 & 0.82 & 0.14 & $18.3 \%$ \\
\hline Europe & 1.00 & 0.46 & 1.04 & 0.99 & 1.01 & 0.91 & 0.86 & 0.12 & $14.2 \%$ \\
\hline EAFA & 1.03 & 0.64 & 0.98 & 0.25 & 1.01 & 0.62 & 0.82 & 0.11 & $18.2 \%$ \\
\hline Pacific & 1.05 & 0.74 & 0.96 & 0.11 & 1.01 & 0.60 & 0.86 & 0.06 & $14.3 \%$ \\
\hline \multicolumn{10}{|c|}{ Country returns } \\
\hline Australia & 1.42 & 1.00 & 0.95 & 0.06 & 0.96 & 0.26 & 0.76 & 0.10 & $24.2 \%$ \\
\hline Belgium & 1.18 & 0.83 & 1.02 & 0.99 & 1.02 & 0.82 & 0.92 & 0.17 & $7.5 \%$ \\
\hline Canada & 1.08 & 0.99 & 0.99 & 0.31 & 1.03 & 0.91 & 0.88 & 0.07 & $11.7 \%$ \\
\hline France & 1.04 & 0.79 & 1.02 & 0.93 & 1.01 & 0.54 & 0.89 & 0.11 & $10.6 \%$ \\
\hline Germany & 1.04 & 0.97 & 1.01 & 0.56 & 1.03 & 0.80 & 0.91 & 0.11 & $9.4 \%$ \\
\hline Italy & 1.05 & 0.71 & 0.95 & 0.18 & 1.05 & 0.79 & 1.01 & 0.69 & $-0.7 \%$ \\
\hline Japan & 1.02 & 0.63 & 0.97 & 0.24 & 1.02 & 0.63 & 0.91 & 0.08 & $8.7 \%$ \\
\hline Netherlands & 1.05 & 0.85 & 0.99 & 0.45 & 1.02 & 0.57 & 0.83 & 0.16 & $16.9 \%$ \\
\hline Sweden & 1.09 & 0.99 & 0.93 & 0.30 & 1.06 & 0.64 & 0.87 & 0.05 & $13.3 \%$ \\
\hline Switzerland & 1.02 & 0.90 & 0.99 & 0.42 & 1.01 & 0.59 & 0.90 & 0.08 & $10.1 \%$ \\
\hline UK & 1.05 & 0.95 & 1.01 & 0.96 & 1.35 & 0.85 & 0.86 & 0.24 & $14.3 \%$ \\
\hline US & 1.04 & 0.88 & 1.04 & 1.00 & 1.04 & 0.88 & 0.89 & 0.20 & $10.9 \%$ \\
\hline
\end{tabular}


Table 5. Continued.

\begin{tabular}{lcccccccc}
\hline \multicolumn{2}{c}{ DP } & \multicolumn{2}{c}{ CAY } & \multicolumn{2}{c}{ TBL } & \multicolumn{2}{c}{ INF } \\
\hline Panel C: Benchmark variables & & & & & & \\
\multicolumn{1}{l}{} & $M S E$ & $P$-value & $M S E$ & $P$-value & $M S E$ & $P$-value & $M S E$ & $P$-value \\
World & 1.00 & 0.48 & 1.14 & 0.96 & 1.04 & 0.89 & 1.04 & 0.78 \\
Europe & 1.00 & 0.55 & 1.14 & 0.96 & 1.07 & 0.90 & 1.07 & 0.84 \\
EAFA & 1.00 & 0.52 & 1.14 & 0.89 & 1.10 & 0.96 & 1.10 & 1.00 \\
Pacific & 1.05 & 0.65 & 0.98 & 0.42 & 1.16 & 0.99 & 1.12 & 1.00 \\
\hline & & & & & & & & \\
World & 1.03 & 0.86 & $M A E$ & $P$-value & $M A E$ & $P$-value & $M A E$ & $P$-value \\
Europe & 1.02 & 0.90 & 1.16 & 0.93 & 1.00 & 0.45 & 0.99 & 0.41 \\
EAFA & 0.99 & 0.41 & 1.14 & 0.91 & 1.01 & 0.64 & 1.03 & 0.68 \\
Pacific & 0.94 & 0.16 & 1.14 & 0.97 & 1.05 & 0.87 & 1.07 & 0.95 \\
\hline
\end{tabular}

We forecast one-year ahead real returns using an out-of-sample window from 1990 to 2013 . For Q1, Q2, Q3, Q4, CAY, and INF, we take publication lags into account by moving the returns forward by one quarter. As an example, for $I P^{4}, \mathrm{CAY}$, and INF, the one-year-ahead excess return is measured from the beginning of April to the end of March next year. We measure statistical significance relative to the prevailing mean model using Diebold-Mariano tests where the null hypothesis is equality of the average loss. We consider absolute error and squared error loss. $M A E$ refers to the mean-absolute-error ratio between the candidate model and the prevailing mean model, while $M S E$ refers to the mean-squared-error ratio between the candidate model and the prevailing mean model. The $P$-values are based on Diebold-Mariano $t$-statistics computed using Newey-West standard errors with one lag. For $I P^{4}$, we also show out-of-sample $R^{2}$ s. Bold font indicates statistical significance at the $10 \%$ level. 
Table 6. Using local and global economic growth to predict individual-country returns.

\begin{tabular}{|c|c|c|c|c|c|c|c|c|c|c|c|c|}
\hline & \multicolumn{3}{|c|}{$I P_{W}^{4}$} & \multicolumn{3}{|c|}{$I P_{U S}^{4}$} & \multicolumn{3}{|c|}{$I P_{L}^{4}$} & \multicolumn{3}{|c|}{$I P_{I \perp}^{4}$} \\
\hline & $\beta$ & $t$ & $R^{2}$ & $\beta$ & $t$ & $R^{2}$ & $\beta$ & $t$ & $R^{2}$ & $\beta$ & $t$ & $R^{2}$ \\
\hline Australia & -4.9 & -3.8 & $18.8 \%$ & -3.5 & -3.0 & $10.1 \%$ & -5.3 & -2.9 & $20.5 \%$ & -3.6 & -1.4 & $6.6 \%$ \\
\hline Belgium & -3.2 & -2.2 & $5.9 \%$ & -0.4 & -0.3 & $0.0 \%$ & -2.2 & -1.8 & $5.6 \%$ & -1.2 & -0.8 & $1.0 \%$ \\
\hline Canada & -2.5 & -2.8 & $8.0 \%$ & -0.5 & -0.6 & $0.3 \%$ & -0.6 & -0.5 & $0.5 \%$ & 2.2 & 1.1 & $3.2 \%$ \\
\hline France & -3.8 & -3.2 & $9.0 \%$ & -1.9 & -1.5 & $2.3 \%$ & -2.8 & -3.1 & $6.3 \%$ & 0.5 & 0.1 & $0.0 \%$ \\
\hline Germany & -3.5 & -2.7 & $7.5 \%$ & -1.9 & -1.6 & $2.4 \%$ & -2.6 & -2.8 & $7.7 \%$ & -1.6 & -0.8 & $0.7 \%$ \\
\hline Italy & -1.7 & -1.5 & $1.3 \%$ & 1.6 & 1.5 & $1.2 \%$ & -0.4 & -0.7 & $0.3 \%$ & 0.9 & 0.5 & $0.5 \%$ \\
\hline Japan & -3.1 & -1.8 & $4.7 \%$ & 0.8 & 0.7 & $0.3 \%$ & -1.3 & -1.4 & $2.5 \%$ & 0.6 & 0.4 & $0.1 \%$ \\
\hline Netherl. & -4.6 & -4.1 & $15.9 \%$ & -2.8 & -2.0 & $6.1 \%$ & -2.5 & -2.9 & $14.3 \%$ & -1.4 & -1.1 & $2.6 \%$ \\
\hline Sweden & -4.9 & -3.6 & $11.0 \%$ & -1.5 & -0.9 & $1.1 \%$ & -3.1 & -4.1 & $10.4 \%$ & -1.8 & -1.0 & $2.1 \%$ \\
\hline Switzerl. & -3.7 & -3.1 & $10.2 \%$ & -2.3 & -2.0 & $4.3 \%$ & -0.5 & -0.5 & $0.5 \%$ & 2.3 & 1.4 & $4.5 \%$ \\
\hline UK & -5.8 & -2.1 & $23.5 \%$ & -5.6 & -2.3 & $22.9 \%$ & -3.8 & -1.5 & $7.6 \%$ & 2.7 & 1.2 & $1.7 \%$ \\
\hline US & -2.5 & -3.3 & $7.5 \%$ & -2.3 & -2.7 & $6.7 \%$ & -2.3 & -2.7 & $6.7 \%$ & -1.2 & -0.8 & $0.9 \%$ \\
\hline
\end{tabular}

We regress one-year ahead (calendar-year) real country returns on EOY growth in global industrial production (in columns $I P_{W}^{4}$ ), on US EOY economic growth (in columns $I P_{U S}^{4}$ ), on local-country EOY economic growth (in columns $I P_{L}^{4}$ ), and on the part of local EOY growth that is orthogonal to world EOY growth (in columns $I P_{L^{\perp}}^{4}$ ). $I P_{L^{\perp}}^{4}$ is the residual from the regression of local-country EOY growth on world EOY growth. The returns are in local currency. We use local inflation rates to compute real returns. Bold font indicates statistical significance at the $5 \%$ level. The sample period is 1970-2013. 
Table 7. Trade openness and return forecastability.

\begin{tabular}{|c|c|c|c|c|c|c|}
\hline \multirow{2}{*}{$\begin{array}{l}\text { Openness } \\
\text { measure }\end{array}$} & \multicolumn{3}{|c|}{ Low } & \multicolumn{3}{|c|}{ High } \\
\hline & $\beta$ & $t$ & $R^{2}$ & $\beta$ & $t$ & $R^{2}$ \\
\hline$(\mathrm{EX}+\mathrm{IM}) / \mathrm{GDP}$ & -3.2 & -3.7 & $10.8 \%$ & -4.1 & -4.9 & $15.9 \%$ \\
\hline EX/GDP & -3.3 & -3.7 & $10.9 \%$ & -4.1 & -4.9 & $15.7 \%$ \\
\hline IM/GDP & -3.3 & -3.9 & $11.8 \%$ & -4.0 & -4.7 & $14.8 \%$ \\
\hline
\end{tabular}

12 developed countries for which we have full-sample data are sorted into two groups conditioned on trade openness. Trade openness is measured as the sum of exports and imports over GDP $((\mathrm{EX}+\mathrm{IM}) / \mathrm{GDP})$, exports over GDP, and imports over GDP, respectively. Sorting is dynamic and takes place annually. The table report results from regressions of equal-weighted real stock returns on EOY global economic growth. Bold font indicates statistical significance at the 5\% level. The sample period is 1970-2013. 
Table 8. Forecasting cyclical GDP.

\begin{tabular}{|c|c|c|c|c|c|c|c|c|c|c|c|c|}
\hline \multirow[b]{2}{*}{$k$} & \multicolumn{3}{|c|}{$I P^{1}$} & \multicolumn{3}{|c|}{$I P^{2}$} & \multicolumn{3}{|c|}{$I P^{3}$} & \multicolumn{3}{|c|}{$I P^{4}$} \\
\hline & $\beta$ & $t$ & $R^{2}$ & $\beta$ & $t$ & $R^{2}$ & $\beta$ & $t$ & $R^{2}$ & $\beta$ & $t$ & $R^{2}$ \\
\hline \multicolumn{13}{|c|}{$\underline{\text { Panel A. Forecasting with global EOY growth }}$} \\
\hline$\overline{1}$ & 0.2 & 1.3 & $3.5 \%$ & 0.1 & 0.9 & $1.3 \%$ & 0.1 & 0.7 & $0.6 \%$ & 0.3 & 6.8 & $16.8 \%$ \\
\hline 2 & 0.2 & 2.4 & $7.4 \%$ & 0.3 & 1.9 & $6.3 \%$ & 0.4 & 2.2 & $6.4 \%$ & 0.4 & 8.3 & $24.5 \%$ \\
\hline 3 & 0.2 & 3.1 & $6.7 \%$ & 0.5 & 2.3 & $10.2 \%$ & 0.5 & 2.7 & $10.6 \%$ & 0.4 & 12.0 & $29.0 \%$ \\
\hline 4 & 0.2 & 2.2 & $2.6 \%$ & 0.4 & 1.9 & $7.0 \%$ & 0.5 & 3.1 & $12.9 \%$ & 0.3 & 6.6 & $23.2 \%$ \\
\hline 5 & 0.1 & 2.1 & $1.5 \%$ & 0.3 & 1.7 & $5.7 \%$ & 0.4 & 3.6 & $11.1 \%$ & 0.3 & 4.2 & $11.2 \%$ \\
\hline 6 & 0.1 & 2.1 & $1.4 \%$ & 0.3 & 1.9 & $4.8 \%$ & 0.4 & 3.0 & $6.1 \%$ & 0.2 & 3.0 & $5.5 \%$ \\
\hline 7 & 0.1 & 0.9 & $0.4 \%$ & 0.3 & 2.2 & $3.3 \%$ & 0.3 & 2.4 & $3.4 \%$ & 0.1 & 2.1 & $2.3 \%$ \\
\hline 8 & 0.0 & 0.6 & $0.2 \%$ & 0.3 & 2.7 & $3.7 \%$ & 0.2 & 1.8 & $2.5 \%$ & 0.0 & 0.2 & $0.0 \%$ \\
\hline 12 & 0.0 & 0.3 & $0.1 \%$ & 0.1 & 0.5 & $0.4 \%$ & 0.0 & 0.4 & $0.1 \%$ & -0.0 & -0.5 & $0.3 \%$ \\
\hline \multicolumn{13}{|c|}{ Panel B. Forecasting with innovations in global EOY growth } \\
\hline$\overline{1}$ & -0.2 & -0.9 & $1.9 \%$ & -0.1 & -0.4 & $0.4 \%$ & -0.1 & -0.5 & $0.3 \%$ & 0.4 & 6.5 & $16.2 \%$ \\
\hline 2 & -0.1 & -0.5 & $0.1 \%$ & 0.1 & 0.4 & $0.5 \%$ & 0.2 & 1.1 & $1.4 \%$ & 0.4 & 7.8 & $23.1 \%$ \\
\hline 3 & -0.0 & -0.2 & $0.1 \%$ & 0.3 & 1.2 & $3.4 \%$ & 0.4 & 2.2 & $5.3 \%$ & 0.4 & 10.9 & $27.1 \%$ \\
\hline 4 & -0.1 & -0.4 & $0.2 \%$ & 0.2 & 1.3 & $2.9 \%$ & 0.4 & 2.8 & $8.2 \%$ & 0.4 & 6.2 & $21.3 \%$ \\
\hline 5 & -0.0 & -0.2 & $0.0 \%$ & 0.2 & 1.2 & $2.3 \%$ & 0.4 & 3.2 & $7.0 \%$ & 0.3 & 3.9 & $10.1 \%$ \\
\hline 6 & 0.0 & 0.4 & $0.0 \%$ & 0.3 & 1.7 & $2.8 \%$ & 0.3 & 2.3 & $3.4 \%$ & 0.2 & 2.7 & $4.9 \%$ \\
\hline 7 & 0.1 & 0.9 & $0.5 \%$ & 0.2 & 1.9 & $2.0 \%$ & 0.2 & 1.5 & $1.1 \%$ & 0.1 & 1.6 & $1.7 \%$ \\
\hline 8 & 0.1 & 1.0 & $0.1 \%$ & 0.2 & 1.9 & $1.7 \%$ & 0.1 & 1.0 & $0.4 \%$ & 0.0 & -0.3 & $0.0 \%$ \\
\hline 12 & 0.1 & 0.8 & $0.6 \%$ & 0.0 & 0.3 & $0.1 \%$ & 0.0 & 0.4 & $0.1 \%$ & -0.1 & -0.7 & $0.4 \%$ \\
\hline
\end{tabular}

For each of the twelve delevoped countries in our sample, we decompose quarterly log real GDP into a cyclical and a trend component using the Hodrick-Prescott (1997) filter. The smoothing parameter is set to 1600 . Next, we use panel regressions to forecast the cyclical component at time $t+k$ using either the 1st, 2nd, 3rd, or 4th quarter global economic growth rate as predictive variable, where $k$ is the forecast horizon in quarters. We report test statistics based on two-way cluster-robust standard errors (cluster by year and by country) which accounts for both time series and cross-sectional dependence, see Thompson (2011). The sample period is 1970 to 2013. 
Table 9. Predicting dividend-price ratios and changes in dividends.

\begin{tabular}{lrrrrrr}
\hline$y_{t+1}$ & $\beta$ & $t$ & $\theta$ & \multicolumn{1}{c}{$t$} & $\gamma$ & $t$ \\
\hline & & \multicolumn{1}{c}{ World } \\
$d p_{t+1}$ & $\mathbf{5 . 0}$ & 5.2 & 0.9 & 14.5 & 0.2 & 0.8 \\
$d g_{t+1}$ & 2.0 & 1.9 & -0.1 & -1.6 & 0.3 & 2.6 \\
& & & Europe & & & \\
$d p_{t+1}$ & $\mathbf{5 . 6}$ & 4.9 & 0.9 & 11.9 & 0.1 & 0.8 \\
$d g_{t+1}$ & 2.0 & 1.4 & -0.1 & -2.3 & 0.2 & 2.1 \\
& & & EAFA & & & \\
$d p_{t+1}$ & $\mathbf{5 . 7}$ & 4.7 & 0.9 & 12.3 & 0.1 & 0.7 \\
$d g_{t+1}$ & 1.8 & 1.3 & -0.1 & -2.4 & 0.2 & 1.9 \\
& & & Pacific & & & \\
$d p_{t+1}$ & $\mathbf{5 . 6}$ & 3.8 & 0.9 & 9.7 & 0.3 & 1.2 \\
$d g_{t+1}$ & 1.8 & 1.5 & -0.0 & -1.2 & 0.2 & 1.0 \\
\hline
\end{tabular}

The table shows results from the regression $y_{t+1}=\alpha+\beta I P_{t}^{4}+\theta d p_{t}+\gamma d g_{t}+\varepsilon_{t+1}$ where $y_{t+1}$ is either the log dividend-price ratio, $d p_{t+1}$, or the log dividend growth rate, $d g_{t+1}$, from, respectively, the world market portfolio, the European portfolio, the EAFA portfolio, and the Pacific portfolio. The regressions use data at the annual frequency. Bold font indicates statistical significance at the $5 \%$ level. The sample period is $1970-2013$. 

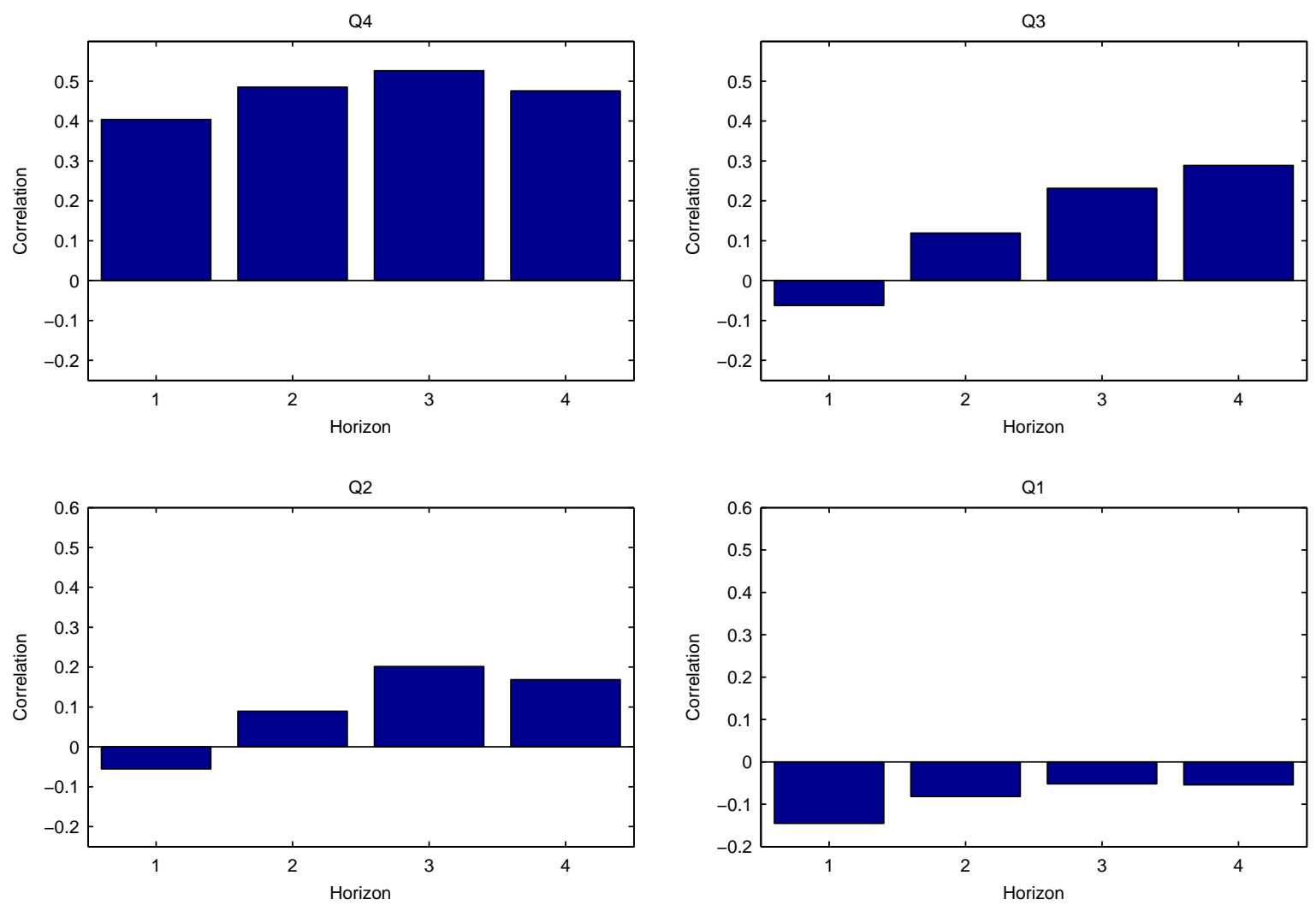

Figure 2. Correlations between innovations to global growth and the future output gap. 